NBER WORKING PAPER SERIES

\title{
RATIONAL CHOICE AND VOTER TURNOUT: EVIDENCE FROM UNION REPRESENTATION ELECTIONS
}

\author{
Henry S. Farber \\ Working Paper 16160 \\ http://www.nber.org/papers/w16160 \\ NATIONAL BUREAU OF ECONOMIC RESEARCH \\ 1050 Massachusetts Avenue \\ Cambridge, MA 02138 \\ July 2010
}

I thank Avinash Dixit, Joanne Gowa, Lawrence Kahn, Alexandre Mas and Jesse Rothstein for helpful comments. I am grateful to the Institute for Advanced Study for providing me with substantial time during a leave to work on this project. The views expressed herein are those of the author and do not necessarily reflect the views of the National Bureau of Economic Research.

NBER working papers are circulated for discussion and comment purposes. They have not been peerreviewed or been subject to the review by the NBER Board of Directors that accompanies official NBER publications.

(C) 2010 by Henry S. Farber. All rights reserved. Short sections of text, not to exceed two paragraphs, may be quoted without explicit permission provided that full credit, including $\odot$ notice, is given to the source. 
Rational Choice and Voter Turnout: Evidence from Union Representation Elections Henry S. Farber

NBER Working Paper No. 16160

July 2010

JEL No. D72,J51

\begin{abstract}
$\underline{\text { ABSTRACT }}$
The standard theoretical solution to the observation of substantial turnout in large elections is that individuals receive utility from the act of voting. However, this leaves open the question of whether or not there is a significant margin on which individuals consider the effect of their vote on the outcome in deciding whether or not to vote.

In order to address this issue, I study turnout in union representation elections in the U.S. (government supervised secret ballot elections, generally held at the workplace, on the question of whether the workers would like to be represented by a union). These elections provide a particularly good laboratory to study voter behavior because many of the elections have sufficiently few eligible voters that individuals can have a substantial probability of being pivotal. I develop a rational choice model of turnout in these elections, and I implement this model empirically using data on over 75,000 of these elections held from 1972-2009.

The results suggest that most individuals (over 80 percent) vote in these elections independent of consideration of the likelihood that they will be pivotal. Among the remainder, the probability of voting is related to variables that influence the probability of a vote being pivotal (election size and expected closeness of the election). These findings are consistent with the standard rational choice model.
\end{abstract}

\author{
Henry S. Farber \\ Industrial Relations Section \\ Firestone Library \\ Princeton University \\ Princeton, NJ 08544-2098 \\ and NBER \\ farber@princeton.edu
}




\section{Introduction and Background}

The economist's equivalent of a Molotov Cocktail in a "mixed" social gathering is to claim that no rational individual should vote in large elections since the chances that this vote will be pivotal in such elections is de minimis. Of course, the fact that so many of us vote presents an interesting puzzle to economists and political scientists, whose solution generally is to assume that individuals derive utility directly from the act of voting. In this study, I investigate the extent to which voters in union representation elections consider the probability that their vote would be pivotal in deciding whether or not to vote.

\subsection{A Brief Review of the Literature}

The rational choice theory of voting has a long history, dating at least to Downs (1957) who recognized that, where voting is costly, individuals will consider both how much they care about the outcome and the likelihood that their vote will influence the outcome (be pivotal). In large elections, the likelihood that an individual's vote will be pivotal is so small as to make it unlikely that the expected benefit of voting will outweigh the costs. This, of course, leads to the difficulty that if elections are large, no one will have the incentive to vote, but, if no one votes, any one vote can determine the outcome so that the incentive to vote will be high.

Without developing it fully, Downs suggested a solution based on the idea that there important private and social benefits to the act of voting that might accrue to individuals and give them the incentive to vote. Riker and Ordeshook (1968) extend Downs's idea in a useful model of the decision to vote that starts with the rational assumption that individuals will vote if their expected utility from voting is higher than their expected utility from not voting. They specify the difference in expected utilities as $R=(B \cdot P)-C+D$, where

- $B$ is the utility gain from getting the preferred outcome,

- $P$ is the probability that the individual's vote will yield the preferred outcome (the probability that the individual is pivotal),

- $C$ is the (non-negative) cost of voting, and

- $D$ is the positive benefit of the act of voting. 
An individual will vote if $R>0$. The innovation is the introduction of $D$, which Riker and Ordeshook attribute to a number of factors having to do with appropriate social and political behavior as well as with personal psychological factors. The key here is that these benefits accrue regardless of whether the individual's vote is pivotal so that $D$, unlike $B$, is not "diluted" by the usual low value for $P$ in large elections.

Frerejohn and Fiorina (1974) present an alternative framework for understanding the voting decision based not on expected utility maximization but on the minimax regret decision criterion. Rather than probability weight outcomes, as in expected utility maximization, the minimax regret criterion has the individual calculate the difference between the utility from voting and the utility from not voting (regret for not voting) for each combination of election outcome and whether or not the individual would have been pivotal. The individual then chooses the option that yields the smallest value for regret. This decision process results in much higher turnout rates in larger elections than does the expected utility maximization model without a direct benefit to voting. ${ }^{1}$

Further refinement of the models and the introduction of game theoretic considerations, where decisions to vote depend on the decisions of others, has occurred. Early models are due to Ledyard (1981) and Palfrey and Rosenthal (1983, 1985), and they demonstrate that there can be substantial turnout even with large electorates. Levine and Palfrey (2007) present a laboratory study of voter turnout that tests some of the implications of the Palfrey and Rosenthal model.

My analysis is clearly in the spirit of the expected utility maximization approach with the possibility of direct utility from the act of voting. The predictions of this model that I examine with the data on union representation elections are similar to those used in the earlier literature. I investigate the extent to which turnout varies inversely with size of election and directly with the expected closeness of the outcome, both of which are systematically related to the likelihood that a vote will be pivotal. I also examine a potential alternative explanation for an inverse relationship between election turnout and size that, in an election where the act of voting is directly observable by others, there may be social pressure in smaller elections that enforces a norm of voting. ${ }^{2}$

\footnotetext{
${ }^{1}$ This work generated substantial critical response. See Strom (1975), Stephens (1975), Mayer and Good (1975), Beck (1975). Frerejohn and Fiorina (1975) respond.

${ }^{2}$ Note that this is distinct from any direct benefit from the act of voting that derives of an underlying
} 


\subsection{Background on Union Representation Elections}

The National Labor Relations Act (NLRA), passed in 1935, codified in law the right of workers in the private sector to be represented by a union of their choice. ${ }^{3}$ This law specified a secret ballot election mechanism that allowed workers to express their preferences for union rpresentation. In broad strokes, a union (or potential union) can petition the National Labor Relations Board (NLRB) to hold an election by a "showing of interest" by workers in the potential bargaining unit. An employer can also request an election if a question arises about workers' preferences for union representation. After issues involving the definition of the appropriate group of workers involved are resolved, the NLRB holds an election. ${ }^{4}$ If the union receives more than 50 percent of the votes cast in the election, then the NLRB certifies that the union is the exclusive representative of the workers for the purposes of collective bargaining. ${ }^{5}$ This certification is valid for one year. If the union and employer reach agreement on a congtract within that period, then the union continues as the bargaining agent of the workers. If the union and employer do not reach agreement within that period, then the union is no longer recognized as the bargaining agent of the workers. ${ }^{6}$

Union representation elections, the vast majority of which are held in the workplace, are an excellent laboratory to examine whether there is, in fact, an important margin on which

norm or belief that does not rely on observability.

3 Additional legislation that served to modify the NLRA includes 1) the Labor-Management Relations (Taft-Hartley) Act, passed in 1947 over President Truman's veto and 2) the Labor-Management Reporting and Disclosure (Landrum-Griffin) Act, passed in 1959.

${ }^{4}$ There are many rules governing employer and union behavior during organizing campaigns, and either side may file "unfair labor practice" charges against the other side with the NLRB. The NLRB adjudicates these charges either before or after the election.

5 The fact that the union needs more than 50 percent implies that unions lose ties. Given the large number of small elections where ties can happen with non-trivial probability, this has implications for the analysis I present below.

6 While not directly related to this study, it has been argued that the election process is too cumbersome and that employers can manipulate the process through coercive means that 1) make it difficult for unions to win these elections (e.g., Weiler, 1983; Freeman, 1985) and, 2) where they win elections, to fail to reach agreement on a first contract (Prosten, 1978). One result of this is a proposed revision to the NLRA, the Employee Free Choice Act (EFCA) that provides for 1) recognition of a union as the bargaining agent of the workers on the basis of a "card check" and 2) first-contract arbitration, whereby an arbitrator sets the terms of the first contract in the event that the union and the employer do not reach agreement. The EFCA is now pending before Congress and many expect some version of this law to be enacted (though perhaps without some of the relevant provisions). See Johnson (2002) for an analysis of the Canadian experience with card check recognition that implies a substantial advantage to unions. 
individuals use the rational voter calculus to decide whether to vote. In at least two ways, these elections are an ideal setting to study voter turnout.

1. There are data on a very large number of elections, each of which is a referendum on a single issue: should workers be represented by a labor union for the purpose of collective bargaining. My analysis sample contains data on over 75,000 elections between 1972 and 2009.

2. A substantial fraction of these elections have a small number of eligible voters; 38 percent have 10 or fewer, 62 percent have 20 or fewer, and 74 percent have 30 or fewer eligible voters.

Thus, there are many elections where a potential voter has a reasonable probability of being pivotal and where the rational voter decision calculus might be important.

A complicating factor is that, unlike political elections, the fact that an organizing drive resulting in an election is held is the result of a decision made by either a labor union (most commonly) or by an independent group of employees. ${ }^{7}$ A union's decision about whether to ask for an election is based, in part, on the likelihood of winning the election. Since the likelihood of a union victory is affected by voter turnout, the selection process yielding an election needs to be explicitly considered.

In the next section, I introduce and discuss the data on election outcomes. I also present a set of facts regarding the level of election activity, union success in elections, and voter turnout that should be explained by a model of voter behavior. In section 3, I present the theoretical framework, including both a model of the union decision to undertake a representation election as well as a model of an individual worker's voting decision. Taken together, these models yield testable implications that allow me to 1) account for the broad set of facts presented as well as 2) shed light on the extent to which voting in these elections is sensitive to factors related to the likelihood that a vote will be pivotal and the extent to which individuals vote due to some direct benefit from the act of voting. In section $4, \mathrm{I}$ present a statistical description of turnout rates, and, in section 5, I implement the model

\footnotetext{
${ }^{7}$ An election can be requested formally by a labor union (95 percent of elections) after a showing of substantial interest through the signing of authorization cards by at least 30 percent of workers in the potential bargaining unit.
} 
empirically. In section 6, I discuss issues related to the interpretation and evaluation of the model, and section 7 concludes.

\section{Data and High-Level Facts}

I have data on 237,022 individual elections involving a single union "closed" by the NLRB between July 1962 and August 2009. ${ }^{8}$ Of these, 213,548 elections are "certification" elections to determine if a union should represent a group of currently non-unionized workers. The remaining 23,474 elections are "decertification" elections to determine if an existing union should continue to represent a group of currently unionized workers. ${ }^{9}$

\subsection{The Level of Election Activity}

In order to set the stage for the theoretical and empirical analyses, I present some aggregate facts regarding the level of election activity over time, union success in elections, and voter turnout.

As shown in Figure 1, the number of certification elections fell sharply in the early 1980s, dropping from about 7,000 per year earlier to less than 2,000 per year later. ${ }^{10}$ Interestingly, at the same time the average size of elections held increased gradually from about 55 workers per election to about 70 workers per election. As I will demonstrate in the next section, this time-series pattern is consistent with unions making optimizing decisions about whether to request an election in an organizing environment that deteriorated in the early 1980s and where unions realize increasing returns to oranization with unit size.

\footnotetext{
8 These are administrative data for federal fiscal years 1963-2009. Early in the period the federal fiscal year ran from July to June before switching to October to September. I recode the earlier fiscal year to run from October to September. On this basis, I have complete data on elections closed during the 1963-2009 fiscal years (other than those closed in September 2009) as well as during the last quarter of the 1962 fiscal year. I have compiled these data over a long period using data received from the NLRB. I thank Alexandre Mas for compiling the data from 1962 through 1972.

${ }^{9}$ In this case, the union is decertified only if a majority of the voters vote to decertify. Thus, the union wins ties in decertification elections.

10 Farber and Western $(2001,2002)$ investigate the causes of this sharp drop.
} 


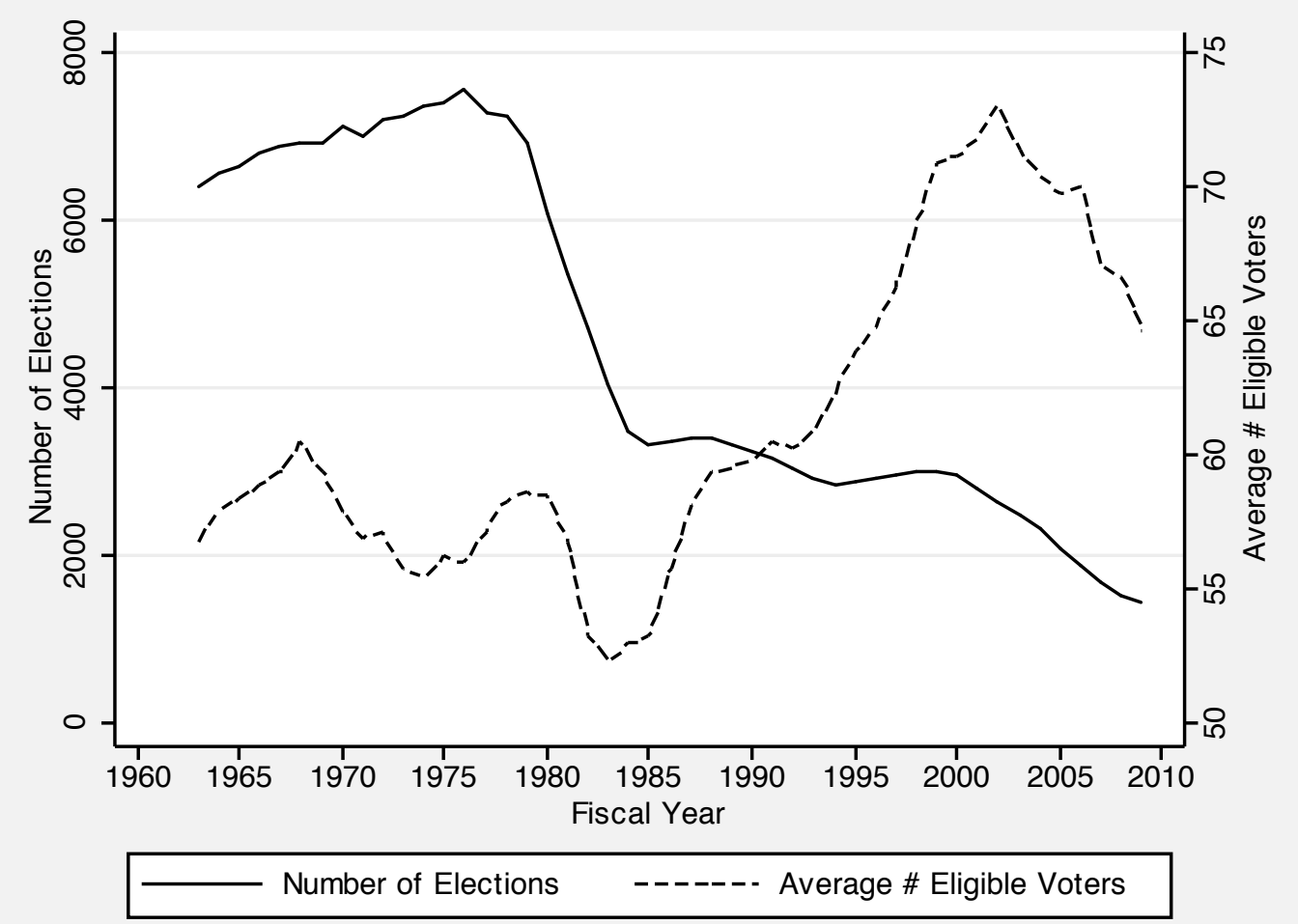

Figure 1: Number of Elections and Average Size of Elections, 5-year moving average

\section{$2.2 \quad$ Union Success in Elections}

The union win rate in elections held (figure 2) fell from over 55 percent in the mid-1960s to less than 45 percent in the early 1980s, then increased to 60 percent by 2005 . The fraction of votes cast that were cast in favor of union representation follows a similar pattern with changes of smaller amplitude. As I discuss below, the pattern since the early 1980s is consistent with an optimizing union in a deteriorating organizing environment making strategic decisions regarding contesting elections of different sizes. ${ }^{11}$

\subsection{Voter Turnout}

There are important data issues in studying voter turnout. In many elections (about onethird) some ballots are challenged by the employer. The NLRB sets these ballots aside and

\footnotetext{
${ }^{11}$ Farber (2001) estimates a model of union win rates and vote shares by election size that accounts for the pattern in figure 2 .
} 


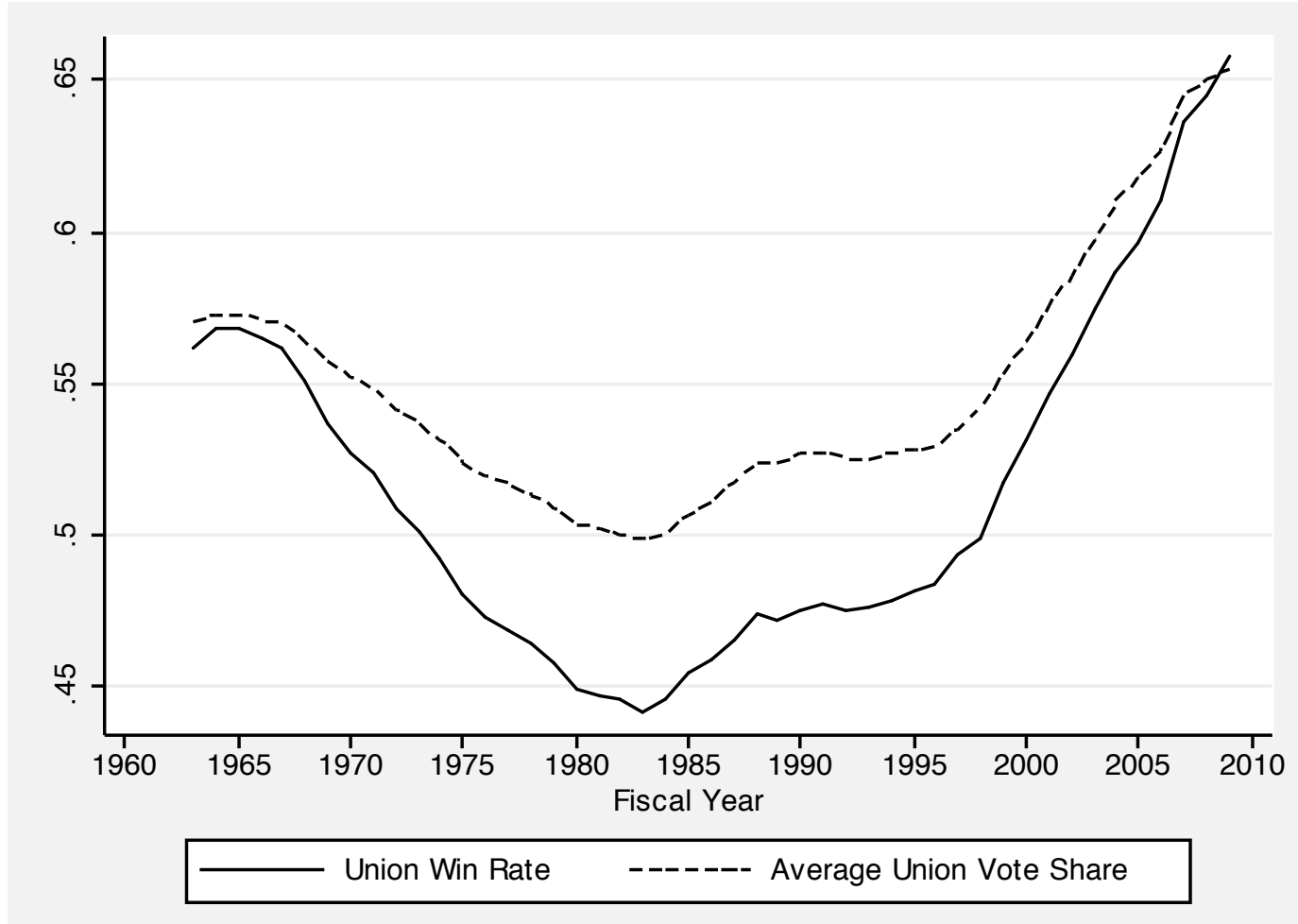

Figure 2: Union Win Rate and Pro-Union Vote Share, 5-year moving average

only investigates their validity if their aggregate number could have changed the election outcome. If they could not change the outcome, they are ignored and their votes are not recorded as pro- or anti-union. If they could change their outcome, at least some are investigated (to the point where the outcome is no longer at issue). The number reported as eligible to vote is the ex ante number, including any workers whose eligibility is later questioned. Thus, a turnout rate calculated as the ratio of the sum of the pro and con votes to the number reported as eligible will not be accurate in the presence of challeges unless all are resolved and the numbers adjusted accordingly.

I proceed by examining turnout only in elections where there are no challenged ballots. While this is likely not a random subset of all elections, it eliminates the important measurement issues. Unfortunately, there are no data on the number of challenged ballots in elections closed before July 1972 or in elections closed between December 1978 and September 1980. Of the 132,869 elections with information on challenged ballots, 79,878 (60.1 percent) had no challenges and can be used for the analysis of turnout. 
Another issue is that a small fraction of elections were carried out by mail ballot or with a combination of on-site and mail balloting (mixed elections) rather than on-site. NLRB procedures regarding representation cases state that mail balloting is used only in unusual circumstances at the discretion of the NLRB Regional Director. ${ }^{12}$ While there is no information on the mode of election prior to fiscal year 1984, fewer than 1 percent of elections between 1984 and 1990 were mail or mixed elections. On this basis, I proceed assuming that all elections prior to fiscal 1984 were carried out on-site.

From 1984 onward, 94 percent of elections were on-site, 4.8 percent were by mail ballot, 0.2 percent were mixed, and the mode is missing for 1 percent. ${ }^{13}$ However, the fraction of elections with mail ballots increased to about 13 percent by 2002 before declining to about 10 percent by 2009. Figure 3 contains a plot of the distribution of election by mode. ${ }^{14} \mathrm{I}$ have no explanation for the increase in use of mail ballots in the last two decades.

I proceed with the analysis using the 77,308 on-site elections wtih no challenges 19722009. I return to the mail ballots later when examining the role of social pressure in voter turnout.

The broad facts regarding mean turnout based on these data are presented in figure 4 . The average turnout rate across on-site elections held steady at about 92 percent until the mid-1990s and has since fallen to about 84 percent. Figure 4 also contains the time series of the aggregate turnout rate (the ratio of the total number of votes across all elections to the total number of eligible voters across all elections). The aggregate turnout rate shows a similar time-series pattern though it falls much more sharply, from 92 percent to 76 percent. The sharper decline of the aggregate turnout rate could reflect a shift in composition of

\footnotetext{
12 The NLRB document, An Outline of Law and Procedure in Representations Cases, ch. 22, states that "Mail balloting is used, if at all, in unusual circumstances, particularly where eligible voters are scattered either because of their duties or their work schedules or in situations where there is a strike, picketing, or lockout in progress. In these situations the Regional Director considers mail balloting taking into consideration the desires of the parties, the ability of voters to understand mail ballots, and the efficient use of Board personnel." NLRB procedures also allow for limited mixed elections, with ballots for those eligible voters who cannot vote in person. This does not include absentees or those who are on vacation. See http://www.nlrb.gov/publications/manuals/r_-_case_outline.aspx. Accessed on September 25, 2009.

13 Not surprisingly, given the fact that mail balloting is used at the discretion of the regional director is that there is substantial variation across the 37 NLRB regions in usage rate of mail balloting. Between 1984 and 2009 the usage rate of mail balloting ranged from less than one percent in Newark and Houston to more than 10 percent in Milwaukee, Peoria, and Seattle.

14 There are a very few mixed-mode elections, and these are ignored in figure 3.
} 


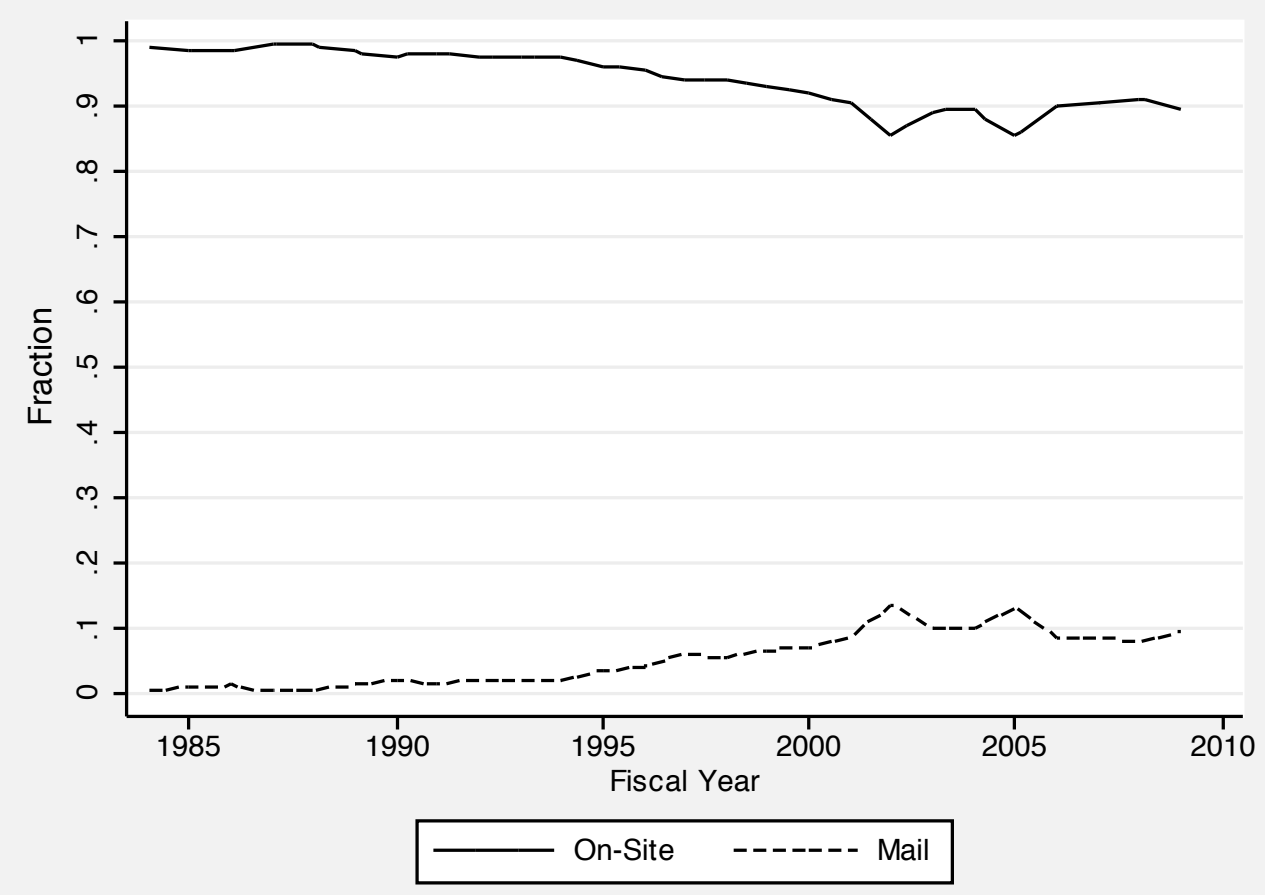

Figure 3: Mode of Election, by Fiscal Year

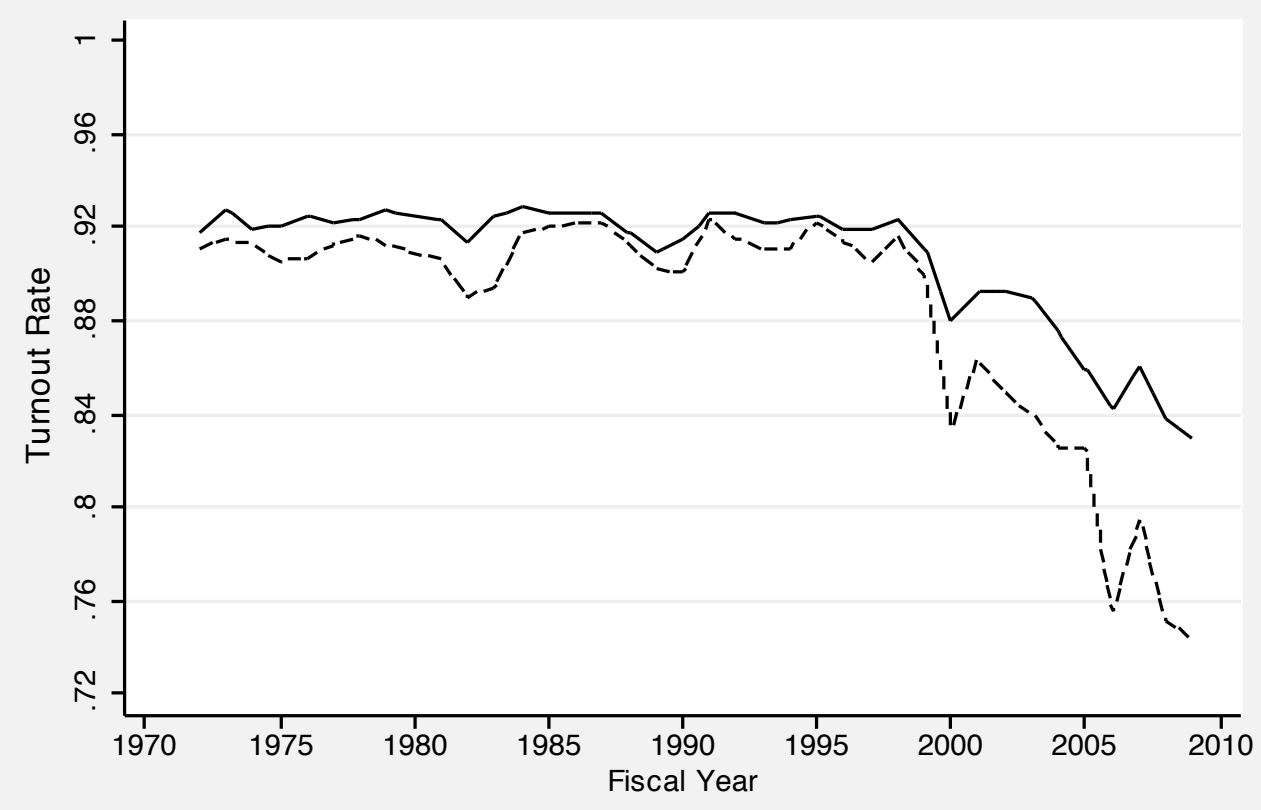

Election Average Turnout

------ Overall Average Turnout

Figure 4: Turnout rate in On-Site Union Represenation Elections 
elections (for example from smaller to larger elections with lower turnout).

One test of the relevance of a rational voter model of turnout is the extent to which the decline evident in figure 4 can be accounted for by the likelihood that a voter will be pivotal. I present this test below.

Turnout rates in union representation elections are very high compared to those we see in the usual political elections. This could reflect several factors. First, these elections are relatively small, averaging 50 to 75 eligible voters (figure 1), so that a worker's vote has a reasonable probability of being pivotal. Second, these elections are about workers' livelihoods, so the stakes can be very high. Third, these elections are generally held at the workplace during working hours, so the cost of voting is relatively low.

\section{Theoretical Framework}

There are three relevant groups of actors in determining the outcomes of representation elections.

- Labor unions who decide which groups of workers to attempt to organize through the election process,

- Employees in workplaces who can vote if an election is held, and

- Employers of non-union workers who can affect both the likelihood of an election being held and the outcome of elections that are held through their treatment of workers and actions during an organizing drive.

In what follows, I do not consider employer behavior directly but understand that unions and workers make decisions considering employer actions.

\subsection{The Union's Decision to Hold a Representation Election}

I begin with modeling the union's decision to hold a representation election. The set of elections that are held is the result of a selection process by labor unions about where to focus their organizing activity. An economically rational labor union will contest elections only where there is a positive expected value associated with the election. This suggests that among all possible potential bargaining units, called "targets" here, elections are more 
likely when the likelihood of a union victory is higher. This has some important implications for the analysis of both the quantity of election activity and election outcomes over time. First, the potential bargaining units in which elections are held at any point in time are not representative of the pool of targets since elections are more likely to be held in places where workers are thought to be favorable to unions. Second, unions may perceive larger benefit to organization in certain types of workplaces, and, in these cases, they will be willing to contest an election even where workers may be less favorably disposed to unions.

Consider a union's decision regarding whether or not to contest an election in a specific target. The union bases its decision on several factors: ${ }^{15}$

- the per-worker benefit to the union of a union victory $(V)$,

- the per-worker cost to the union (net of union dues) of negotiating a contract and administering a unionized workplace $\left(C_{a}\right)$,

- the per-worker cost to the union of the organization effort $\left(C_{o}\right)$, and

- the probability of a union victory in an election $(\theta)$.

The definition of the benefits and costs as per-worker organized (the number of eligible workers, $N)$ is simply a normalization that eases exposition.

Define the per-worker expected value to the union of contesting an election at target $i$ as

$$
V_{i}=\theta_{i}\left(V_{i}-C_{a i}\right)-C_{o i}
$$

A rational union will undertake to organize the target if $V_{i}$ is positive. This implies that the condition for an election to be held is

$$
\theta_{i}>\frac{C_{o i}}{\left(V_{i}-C_{a i}\right)}
$$

The right hand side of equation 2 defines a critical value for the probability of a union victory. This is

$$
\theta_{i}^{*}=\frac{C_{o i}}{\left(V_{i}-C_{a i}\right)},
$$

and unions will contest elections where $\theta_{i}>\theta_{i}^{*}$.

\footnotetext{
15 I abstract here from the fact that a union victory in many cases does not result in the successful negotiation of a contract. This difficulty in negotiating a first contract has increased over time. While there are no systematic data on representative samples of union-won elections, Weiler (1984) analyzed a small number of surveys and found that the fraction of union wins yielding first contracts fell from 86 percent in 1955 to 63 percent in 1980. See also, Prosten (1978) and Cooke (1985).
} 


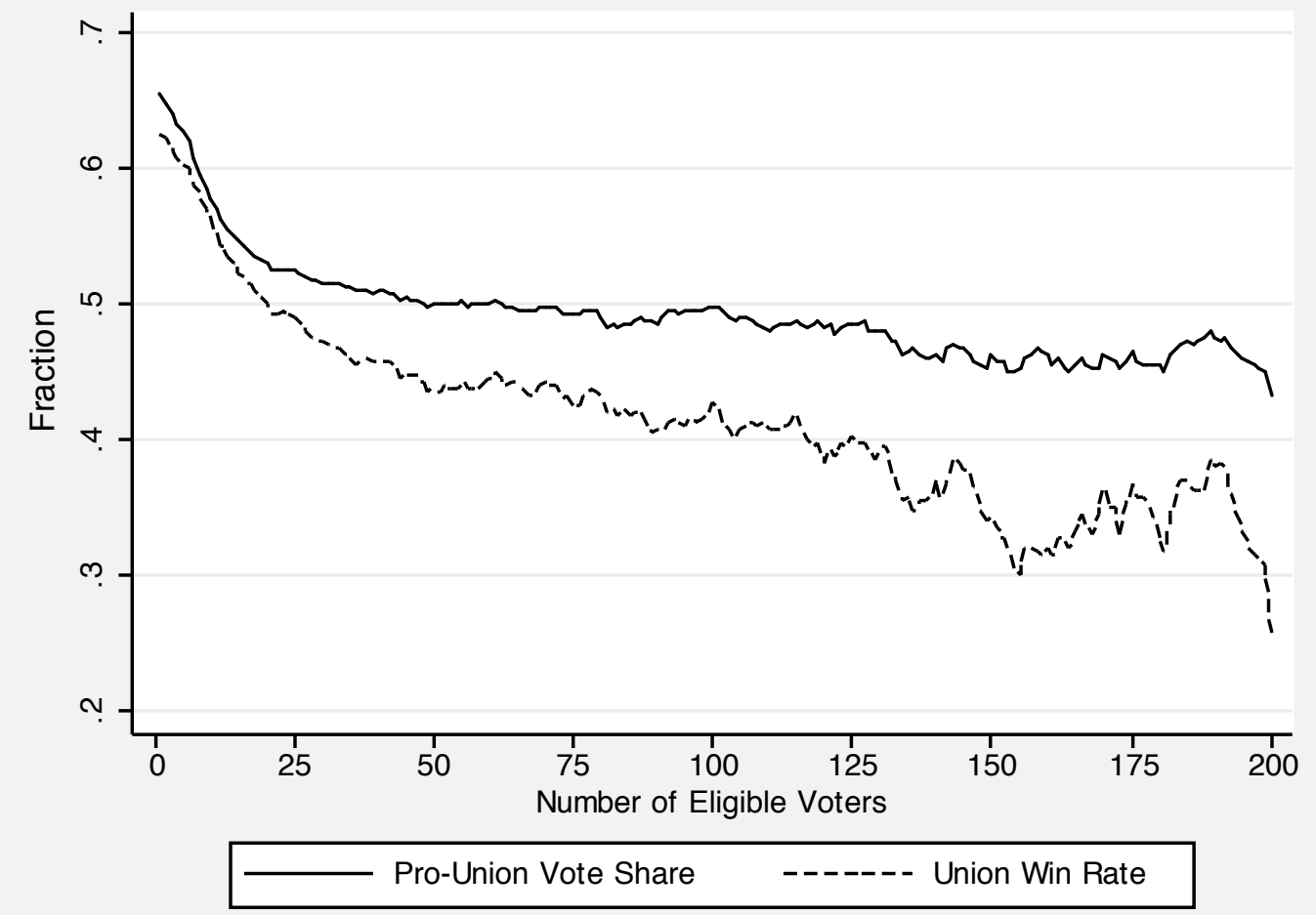

Figure 5: Union Win Rate and Pro-Union Vote Share, by Election Size (5-voter moving average)

An important characteristic of the target is its size $\left(N_{i}\right)$. Size has a direct effect on the probability of a union victory. The number of workers could also have an important effect on the appeal of the target to the union even holding the probability of a union victory fixed. A union victory in a large election could have important positive spillovers for the union in terms of bargaining leverage and "marketing" value in other organizing campaigns $\left(\frac{\partial V_{i}}{\partial N_{i}}>0\right)$. Additionally, there may be decreasing costs per worker of holding the organizing drive $\left(\frac{\partial C_{o i}}{\partial N_{i}}<0\right)$ and/or decreasing costs per member of servicing a bargaining unit once there is a union victory $\left(\frac{\partial C_{a i}}{\partial N_{i}}<0\right)$. Together, these imply that the critical value for the probability of a union victory is decreasing in election size $\left(\frac{\partial \theta_{i}^{*}}{\partial N_{i}}<0\right)$ so that unions will contest larger elections where they have a smaller chance of winning. This selection by unions implies that observed union win rates will be negatively related to the number of eligible voters.

This prediction is supported by evidence on union win rates in elections of various sizes. Figure 5 contains plots of the union win rate and pro-union vote share rate in elections by 
number of eligible voters. Consistent with the union selection model, union win rates and pro-union vote shares fall with election size.

Substantial evidence exists that the political and legal environment for unions worsened substantially in the early 1980's (Weiler (1990), Gould (1993), and Levy (1985)). This could affect both the distribution of $\theta$ and the cost of organization to the union $\left(C_{o}\right)$. A shift to the left in the distribution of $\theta$ (implying fewer good targets for organization) does not, by itself, imply a change in the critical value for the probability of a union victory $\left(\theta^{*}\right)$. The firstorder result will be that fewer elections will be held. But, since the selection rule remains unchanged, union success in elections that are held will not be greatly affected. ${ }^{16}$ However, if the adverse changes in the organizing environment increase the cost of organization $\left(C_{o}\right)$, the result will be an increase in $\theta^{*}$ implying that the set of elections actually contested will become more favorable to unions. Taken together, the effects of adverse changes in the organizing environment on the distribution of $\theta$ and on $C_{o}$ will result in fewer elections held but greater union success in those elections that are held. This is consistent with the evidence presented in figures 1 and 2 .

The key lesson to take away from this model is that any analysis of voting behavior and election outcomes must take into account the union selection process regarding where to contest elections.

\subsection{Voting Decisions of Workers and Election Outcomes}

In a rational voter model, the decision to vote is based on a comparison of expected utility conditional on voting $(E(U \mid V))$ with expected utility conditional on not voting $(E(U \mid N V))$. Expected values are used since the outcome of the election is uncertain.

Consider the following framework, which borrows heavily from the analysis of Coate, Conlin, and Moro (2008). In a given workplace, the expected fraction of workers who are pro-union is denoted by $\mu$. These workers, if they vote, vote in favor of union representation. Similarly, anti-union workers, if they vote, vote against union representation. Pro-union workers receive a benefit of $b_{p}>0$ if the union wins the election. Anti-union workers receive a "benefit" of $b_{c}<0$ if the union wins the election. For simplicity, I assume $b_{p}=-b_{c}=b$ in

\footnotetext{
${ }^{16}$ In fact, the extent to which union success will be affected depends on the underlying distribution of $\theta$ before and after the shift.
} 
what follows.

I define $C_{i}$ as the cost of voting to worker $i$ net of the direct benefit worker $i$ receives from the act of voting itself, independent of any expected benefit that comes from the possibility that his vote would alter the election outcome. As such, $C_{i}$ may well be negative. ${ }^{17}$ I assume $C_{i}$ varies across workers and is distributed with $\mathrm{CDF} G(\cdot)$.

Consider first a pro-union worker $i$. The change in his expected utility if he votes is the probability that his vote is pivotal times $b$ less the cost of voting $\left(C_{i}\right)$. The NLRA specifies that the union is certified as the bargaining agent of the workers if and only if a majority of those voting vote in favor. Thus, unions lose ties. On this basis, a pro-union worker's vote will be pivotal only if the election would be tied without his vote. Denote the probability that the vote would be tied without his vote by $\Delta W_{+}$. On this basis, a pro-union worker will vote if

$$
C_{i} \leq b \Delta W_{+}
$$

Given the assumed distribution for costs and noting that $\mu$ represents the probability that a randomly selected worker is pro-union, the probability that a worker votes in favor of union representation is

$$
p_{p}=\mu G\left(b \Delta W_{+}\right) .
$$

The voting decision of an anti-union worker is analogous. The change is his expected utility if he votes is the probability that his vote is pivotal times $b$ less the cost of voting $\left(C_{i}\right)$. Given the fact that unions lose ties, an anti-union worker's vote will be pivotal only if the union would win with a plurality of a single vote without his vote. Denote the probability of a union win by a single vote if without his vote by $\Delta W_{-}$. On this basis, an anti-union worker will vote if

$$
C_{i} \leq b \Delta W_{-} .
$$

Given the assumed distribution for costs, the probability that a worker votes against union representation is

$$
p_{c}=(1-\mu) G\left(b \Delta W_{-}\right) .
$$

The turnout rate in the election is

$$
p_{v}=p_{p}+p_{c}=\mu G\left(b \Delta W_{+}\right)+(1-\mu) G\left(b \Delta W_{-}\right) .
$$

\footnotetext{
17 In the notation of Riker and Ordeshook (1968), $C_{i}$ (the net cost of voting) is $C+D$ (the sum of the cost of voting $(C)$ and the direct benefit of voting $(D)$.
} 
The probability that a worker does not vote (the abstention rate) is

$$
p_{a}=1-p_{v}=1-\mu G\left(b \Delta W_{+}\right)-(1-\mu) G\left(b \Delta W_{-}\right) .
$$

Assuming that individuals' decisions to vote are independent in a given election, the number of pro-, anti-, and non-votes $\left(n_{p}, n_{c}\right.$, and $n_{a}$ respectively) has a multinomial distribtion such that

$$
\operatorname{Pr}\left(n_{p}, n_{c}, n_{a}\right)=\frac{N !}{n_{p} ! n_{c} ! n_{a} !} p_{p}^{n_{p}} p_{c}^{n_{c}} p_{a}^{n_{a}}
$$

where $N=n_{p}+n_{c}+n_{a}$ is the total number of eligible voters. Given the multinomial distribution for the vote counts defined in equation 10 and the fact that unions win an election when more than half the votes cast are cast in favor of union represenation, the probability of a union victory, denoted by $\theta$, is

$$
\theta=\sum_{n_{p}=1}^{N} \sum_{n_{c}=0}^{\operatorname{Min}\left[n_{p}-1, N-n_{p}\right]} \operatorname{Pr}\left(n_{p}, n_{c}, n_{a}\right) .
$$

\subsubsection{Pivotal Pro-Union Workers}

The probability that a pro-union worker's vote is pivotal (the probablity of a tie not including the vote of worker $i$ ), based on the multinomial distribution for the vote counts, is

$$
\Delta W_{+}=\operatorname{Pr}\left(n_{p}=n_{c}\right)=\sum_{i=0}^{I N T(n / 2)} \frac{n !}{i ! i !(n-2 i) !} p_{p}^{i} p_{c}^{i} p_{a}^{n-2 i}
$$

where $n=N-1$, the number of eligible voters less one and $I N T(\cdot)$ returns the truncated integer value of its argument. This rather complicated expression has several key properties:

1. The probability that a pro-union worker's vote is pivotal tends to fall with the number of eligible voters. This underlies the usual result that the probability that a voter is pivotal falls with election size.

2. Holding election size fixed, $\Delta W_{+}$varies directly with the gap between $P_{p}$ and $P_{c}$. The probability of a tie is maximized when $P_{p}=P_{c}$.

3. The marginal effect of a change in the gap between $P_{p}$ and $P_{c}$ on $\Delta W_{+}$falls with election size. This is a direct result of the fact that a for a given difference in vote probabilites, a single vote will be more likely to be pivotal in a smaller election. 
4. $\Delta W_{+}$tends to be larger when the total number of eligible voters is odd than when it is even. This is particularly true when the probability of abstention is low and the number of eligible voters is small. The intuition for this result becomes clearer when considering the case where all workers vote $\left(p_{a}=0\right)$. In this case, the probability of a tie among all voters but one is uniquely zero when $N$ is even. The $n=N-1$ votes, an odd number, cannot be split equally. However, the probability of a tie among the $n=N-1$ voters is positive for odd values of $N$ and decreasing with $N$.

\subsubsection{Pivotal Anti-Union Workers}

A similar analysis follows for anti-union workers. The probability that an anti-union worker's vote is pivotal is the probablity that the union wins by one not including the vote of worker $i$. Based on the multinomial distribution for the vote counts, this is

$$
\Delta W_{-}=\operatorname{Pr}\left(n_{p}=n_{c}+1\right)=\sum_{i=0}^{I N T((n-1) / 2)} \frac{n !}{(i+1) ! i !(n-2 i-1) !} p_{p}^{i+1} p_{c}^{i} p_{a}^{n-2 i-1}
$$

With some modification, this expression has key properties similar to $\Delta W_{+}$.

1. As with the probability of a tie, the probability that an anti-union worker's vote is pivotal tends to fall with the number of eligible voters. This further supports the usual result that the probability that a voter is pivotal falls with election size.

2. Holding election size fixed, $\Delta W_{-}$, the probability of a union plurality of one vote is maximized when $P_{p}$ is slightly greater than $P_{c}$, with the optimal gap falling with election size. In this case it is (approximately) true that $\Delta W_{-}$varies directly with the gap between $P_{p}$ and $P_{c}$.

3. As before, the marginal effect of a change in the gap between $P_{p}$ and $P_{c}$ on $\Delta W_{-}$falls with election size.

4. $\Delta W_{-}$tends to be larger when the total number of eligible voters is even than when it is odd. This effect is stronger when the probability of not voting $\left(p_{a}\right)$ is small and the number of eligible voters is small. In the case where all workers vote $\left(p_{a}=0\right)$, the probability of a union victory by a single vote is uniquely zero when $N$ is odd. The $n=N-1$ votes, an even number, cannot be split to yield a plurality of a single vote. 
However, the probability of a single-vote union victory among the $n=N-1$ voters is positive for even values of $N$ and decreasing with $N$.

\subsubsection{Empirical Predictions}

The central analytic difficulty is that the probabilities of being pivotal depend on the decisions of all voters. As such, an equilibrium concept is needed to define the outcome. A natural assumption is a symmetric Nash equilibrium such that all voters are making decisions regarding whether to vote consistent with equations 4 or 6 , as appropriate, conditional on common information regarding fraction pro-union $(\mu)$ and the distribution of costs $(G(\cdot)$, and benefit of getting the preferred outcome $(b)$. However, it is not possible to derive closed form solutions for $p_{p}$ and $p_{c}$ because the expressions for the proabilities of being pivotal are complicated and depend on $p_{p}$ and $p_{c}$.

However, as described above there are important empirical predictions of the model. These include

1. Turnout will fall as the cost of voting increases.

2. Turnout will fall with election size.

3. The pro-union vote share will be larger in elections with an odd number of eligble voters than in an election with an even number of eligible voters. Restated, the antiunion vote share will be larger in elections with an even number of eligible voters than in an election with an odd number of eligible voters.

4. Holding election size fixed, turnout will increase with the expected closeness of ex ante preferences for and against union representation.

5. The marginal effect on turnout of an increase in expected closeness of preferences will fall with election size.

\subsection{An Alternative Explanation: Social Pressure}

One reason why individuals may vote even when their probability of being pivotal is very small is that a norm exists where-by "good citizens" vote. ${ }^{18}$ It may or may not be the case

18 See, for example, Knack, 1992. 
that the observability of the act of voting is an important component in enforcing a voting norm. In the context of union representation elections, if observability is important, then turnout would be higher in on-site elections, observability voting is straightforward and likely more effective than in mail elections, where observability is difficult, if not impossible. This higher social pressure to vote in on-site elections as a negative cost of voting and implies that turnout will be lower in mail elections than in on-site elections.

Another prediction of the social pressure model is that, because observability is likely more difficult in larger on-site elections than in smaller on-site elections, the resulting diminution of social pressure in larger elections could account for a negative relationship between turnout and election size. Funk (2008) presents evidence consistent with this idea. She analyzes turnout in Swiss elections, where an option to vote by mail was introduced in order to encourage voting. The idea is that voting by mail in general elections reduces the cost of voting by eliminating the need to travel to the polling place. ${ }^{19}$ However, voting by mail, even in general elections, may also reduce social pressure by reducing observability as individuals can claim they voted by mail. Funk finds that there was very little effect on overall turnout in the Swiss "natural experiment," suggesting that the cost reduction of voting by mail was largely offset by the reduction in social pressure. She confirms this with a finding that turnout was more negatively affected in smaller communities, where presumably there is more social pressure due to easier observability by the community at large.

This suggests a test of the competing models predicting an inverse relationship between turnout and election size. The economic model predicts that turnout will fall with election size regardless of the mode of the election. The social-pressure model predicts that turnout will fall with election size only in on-site elections (as individual votes are less obvious to the whole community). Evidence that the marginal effect of election size on turnout is smaller in mail elections than in on-site elections would imply that social pressure is important. I implement this test in my empirical analysis.

\footnotetext{
19 This is in contrast to the NLRB representation elections analyzed here because the on-site elections are held at the work-place, so that no special trip is required.
} 


\section{A Statistical Description of Turnout Rates}

The simplest statistical model of the turnout rate is a binomial model that is derived from the multinomial model of the pro-union, anti-union, abstain vote decision specified in equation 10. In this model the probability that a worker in election $j$ votes is $p_{j}$ and the probability that a worker in election $j$ does not vote is $1-p_{j}$. The number of votes cast in election $j$ $\left(V_{j}\right)$ with $N_{j}$ eligible voters in this model has a binomial distribution such that

$$
\operatorname{Pr}\left(V_{j}\right)=\frac{N_{j} !}{V_{j} !\left(N_{j}-V_{j}\right) !} p_{j}^{V_{j}}\left(1-p_{j}\right)^{N-V_{j}} .
$$

Given that voting probabilities vary across elections and in order to restrict the probability to the unit interval, I specify $p_{j}$ as a linear function of a vector of variables, $X_{j}$ so that $p_{j}=X_{j} \beta$, and this is also the expected turnout rate.

While a model such as this may fit mean turnout rates quite well, it does not tell the whole story. If there is unmeasured heterogeneity across elections (heterogeneity that is not captured by the variables in $X$ ), then this model will underpredict dispersion across elections in turnout rates. This is an example of the well-known problem of over-dispersion in count models.

Consider the following simple descriptive statistical model. Suppose that I model the vote probability in election $j$ as an unconstrained function of the number of eligible voters. In this case the maximum likelihood estimate of $p_{j}$ is the overall ratio across all elections of a given size of the number of votes cast to the total number of eligible voters. This is equivalent to specifying $p_{j}$ to be a function of a complete set of fixed effects for the number of eligible voters. This model will fit average turnout in elections of a given size perfectly, but it has trouble with higher moments. For example, the probability of full turnout is

$$
\operatorname{Pr}\left(T_{j}=1\right)=p_{j}^{j}
$$

and this is strongly underpredicted by the simple binomial model

A simple illustration that this is so is presented in Figure 6, which contains a plot of both the observed probability of full turnout in on-site elections and the predicted probability based on the average turnout rate in on-site elections of a particular size. ${ }^{20}$ The predicted

\footnotetext{
20 This illustration is restricted to on-site elections, which make up 97.4 percent of all elections, for clarity. I will revisit the issue of mail elections in a later section.
} 


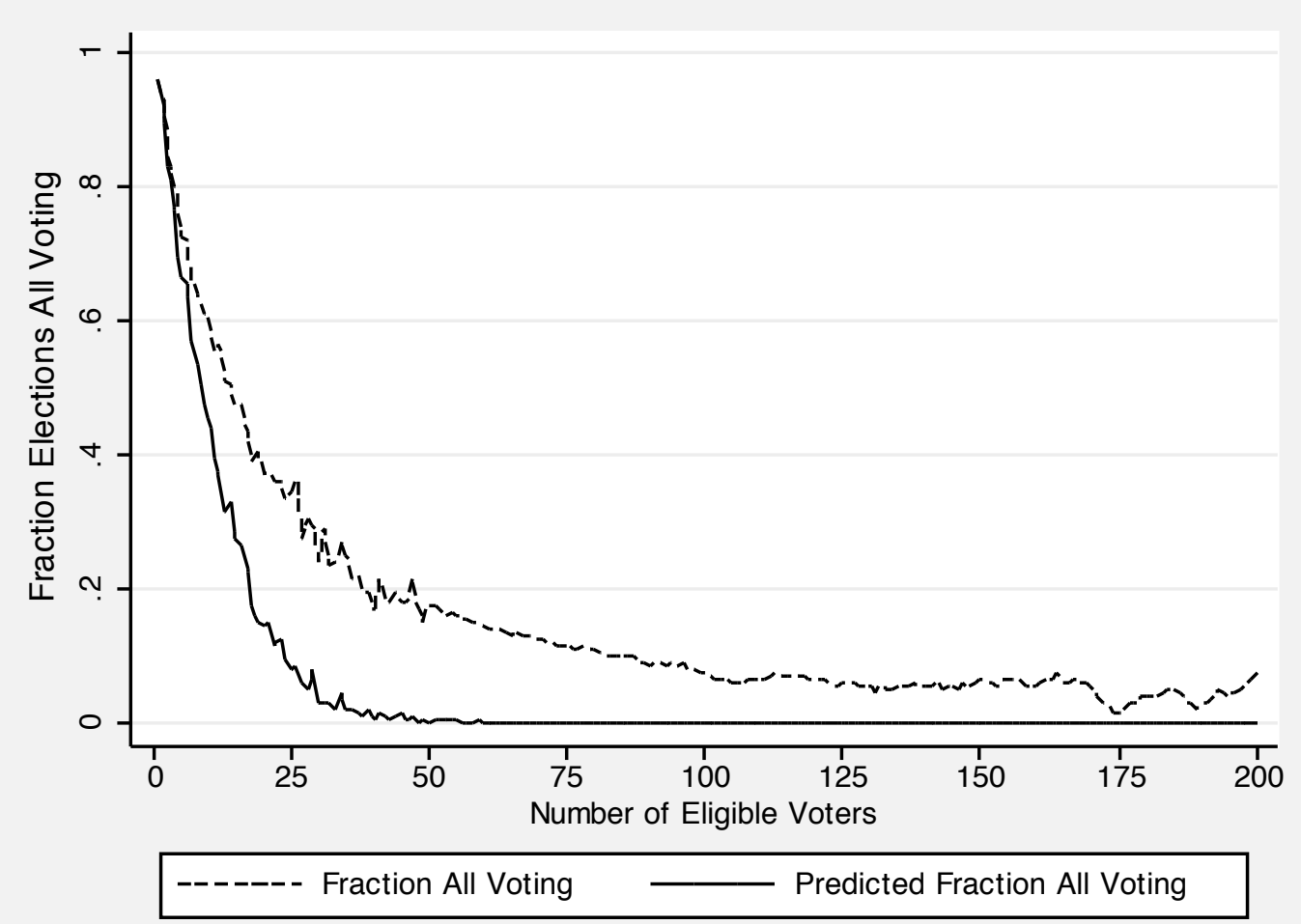

Figure 6: Probability of Full Turnout, by Total Number of Eligible Voters. The predicted fraction $=\bar{p}_{j}^{j}$ and is based on the binomial distribution.

probability of full turnout in an election with $j$ eligible voters is $\bar{p}_{j}^{j}$, where $\bar{p}_{j}$ represents the observed turnout rate in on-site elections with $j$ eligible voters. ${ }^{21}$ It is clear that this simple model substantially underpredicts the likelihood of full turnout. Given observed average turnout rates, the predicted probability of full turnout is virtually zero in elections with 50 or more eligible voters. However, a substantial fraction of these elections (11.3 percent) have full turnout.

The underlying source of this over-dispersion is variation across elections of a given size in the probability of a worker voting. One approach to solving this problem is to assume a particular distribution for the probability of a worker voting in a particular election. A commonly-used distribution for this purpose is the beta distribution. This distribution has positive density only on the unit interval, and it has the additional advantage of yielding a

\footnotetext{
${ }^{21}$ Due to the relative scarcity of larger elections, the actual fraction of elections with full turnout presented as a moving average $(-5,+5)$ for elections with 50 or more eligible voters.
} 
tractable result when mixed with the binomial distribution. On this basis, I assume that $p$ is distributed as beta such that

$$
f(p ; a, b)=\frac{\Gamma(a+b)}{\Gamma(a) \Gamma(b)} p^{a-1}(1-p)^{b-1}
$$

where $a$ and $b$ are positive parameters and $\Gamma$ is the gamma function defined as

$$
\Gamma(x)=\int_{0}^{\infty} \exp (-z) z^{x-1} d z
$$

By the Bayes theorem, the distribution of $p$ conditional on observing $v$ votes cast among $N$ eligible voters is

$$
f(p \mid v)=\frac{h(v \mid p) g(p)}{f(v)} .
$$

Assuming a binomial distribution for votes in a given election, the probability of observing $v$ votes cast among $\mathrm{N}$ eligible voters conditional on $p$ is

$$
h(v \mid p)=\left(\begin{array}{c}
N \\
v
\end{array}\right) p^{v}(1-p)^{N-v}
$$

Given that $p$ has a beta distribution, the unconditional distribution of the number of votes cast is beta-binomial. This is

$$
f(v)=\left(\begin{array}{c}
N \\
v
\end{array}\right) \frac{\Gamma(a+b) \Gamma(a+v) \Gamma(b+N-v)}{\Gamma(a) \Gamma(b) \Gamma(N+a+b)} .
$$

It is convenient to reparameterize the beta distribution in terms of $m=\frac{a}{(a+b)}$ and $\alpha=a+$ $b$. The expected value of $p$ is $m$, and the variance of $p$ is $\sigma^{2}=\frac{m(1-m)}{(1+\alpha)}$. This parameterization yields a density function for $p$ of ${ }^{22}$

$$
g(p ; m, \alpha)=\frac{\Gamma(\alpha)}{\Gamma(m \alpha) \Gamma((1-m) \alpha)} p^{m \alpha-1}(1-p)^{(1-m) \alpha-1} .
$$

The expression for the unconditional distribution of number of votes cast is

$$
f(v)=\left(\begin{array}{c}
N \\
v
\end{array}\right) \frac{\Gamma(\alpha) \Gamma(m \alpha+v) \Gamma((1-m) \alpha+N-v)}{\Gamma(m \alpha) \Gamma((1-m) \alpha) \Gamma(N+\alpha)} .
$$

Overdispersion is captured by the parameter $\alpha$. As $\alpha \rightarrow \infty$, the variance of $p$ goes to zero.. Smaller values of $\alpha$ imply positive variance in the expected fraction voting across elections.

\footnotetext{
22 The beta distribution has a flexible functional form. The distribution is unimodal (inverse U-shaped) if $m \alpha>1$ and $(1-m) \alpha>1$. Otherwise, the distribution is bimodal (U- or J- shaped). A special case is that the distribution is uniform if $\alpha=2$ and $m=0.5$.
} 
Table 1: Binomial and Beta-Binomial Model Model of Voter Turnout

\begin{tabular}{l|cc} 
Variable & Binomial & Beta-Binomial \\
\hline Determinants of $m$ & $(1)$ & $(2)$ \\
\hline Constant & 0.8406 & 0.8620 \\
& $(0.0016)$ & $(0.0032)$ \\
$1 / \sqrt{N}$ & 0.1260 & 0.1458 \\
& $(0.0019)$ & $(0.0031)$ \\
Year FE's & Yes & Yes \\
\hline$\alpha$ & ---- & 6.756 \\
& & 0.064 \\
\hline Log L & -210379.7 & -126336.9
\end{tabular}

This model is estimated by maximum likelihood over the sample of 75,300 on-site elections (with a total of 2,014,616 elgibile voters) with no challenged ballots, between 2 and 200 eligible voters and at least 2 votes cast. The base fiscal year is 2000. Asymptotic standard errors are in parentheses.

In order to evaluate this model, I start by estimating a binomial model of the turnout rate at the election level where the probability of that an individual votes $\left(p_{j}\right)$ is a linear function of the inverse square root of the number of eligible voters. ${ }^{23}$ I estimate this model using the sample of 75,300 on-site elections with 2-200 eligible voters and at least two votes cast. The estimates of this model are contained in the first column of table 1, and they verify that, as expected, turnout falls with election size.

The second column of table 1 contains estimates of the beta-binomial model. This model adds a single parameter $(\alpha)$ that controls the degree of dispersion in the vote probability. Note that there is virtually no difference in the estimates of the coefficients of the mean probability of voting function between the beta and beta-binomial models. However, the estimate of $\alpha$ in the beta-binomial model as well as the substantial improvement in the loglikelihood function between the binomial and the beta-binomial models implies that there is significant variation in the voting probability across elections of a given size.

While I do not present the results here, I have also estimated the model including additional controls for 38 NLRB regions, 9 broad occupational groups, and 9 broad industry

${ }^{23}$ The inverse square root function is a parsimonious specification that does a good job fitting the change in turnout with election size. 


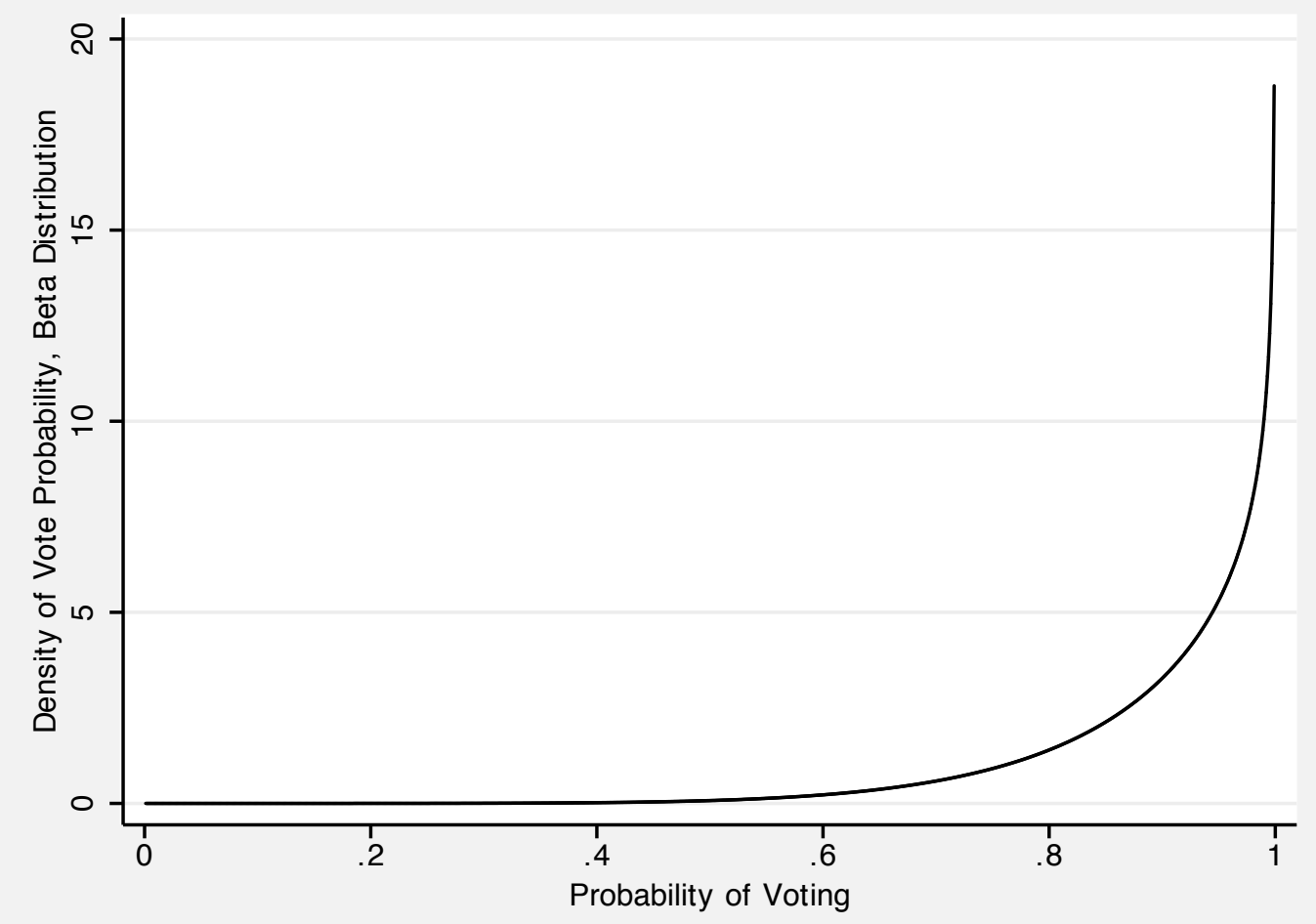

Figure 7: Beta Density Function of Vote Probability (Based on $m=0.9, \alpha=6.756$ ).

groups. ${ }^{24}$ Adding these controls has no substantive effect on the coefficient of interest (the coefficient of $1 / \sqrt{N}$. The estimate of $\alpha$ increases to 7.51, consistent with the idea that there is less unobserved heterogeneity across election sites once variation in region, industry, and occupation are accounted for directly.

Figure 7 contains a plot of the estimated density function for $p$ assuming a mean turnout rate of $m=0.9$ and $\alpha=6.756$ in fiscal year 2000, as estimated. The value for $m$ of 0.9 corresponds to an election with 15 eligible voters in fiscal year 2000 based on the betabinomial estimates, and implied median turnout rate is 0.934 . The figure illustrates that there are many elections with very high expected vote probabilities. The standard deviation of this distribution is 0.108 , and the 75 th and 90 th percentiles of this distribution are 0.978 and 0.993 respectively.

\footnotetext{
24 The industry coding changed in FY2000, and it was not possible to construct a reliable crosswalk between the two coding systems. As a result, I include separate sets of industry controls for the pre-2000 period and for the 2000-and-later period.
} 


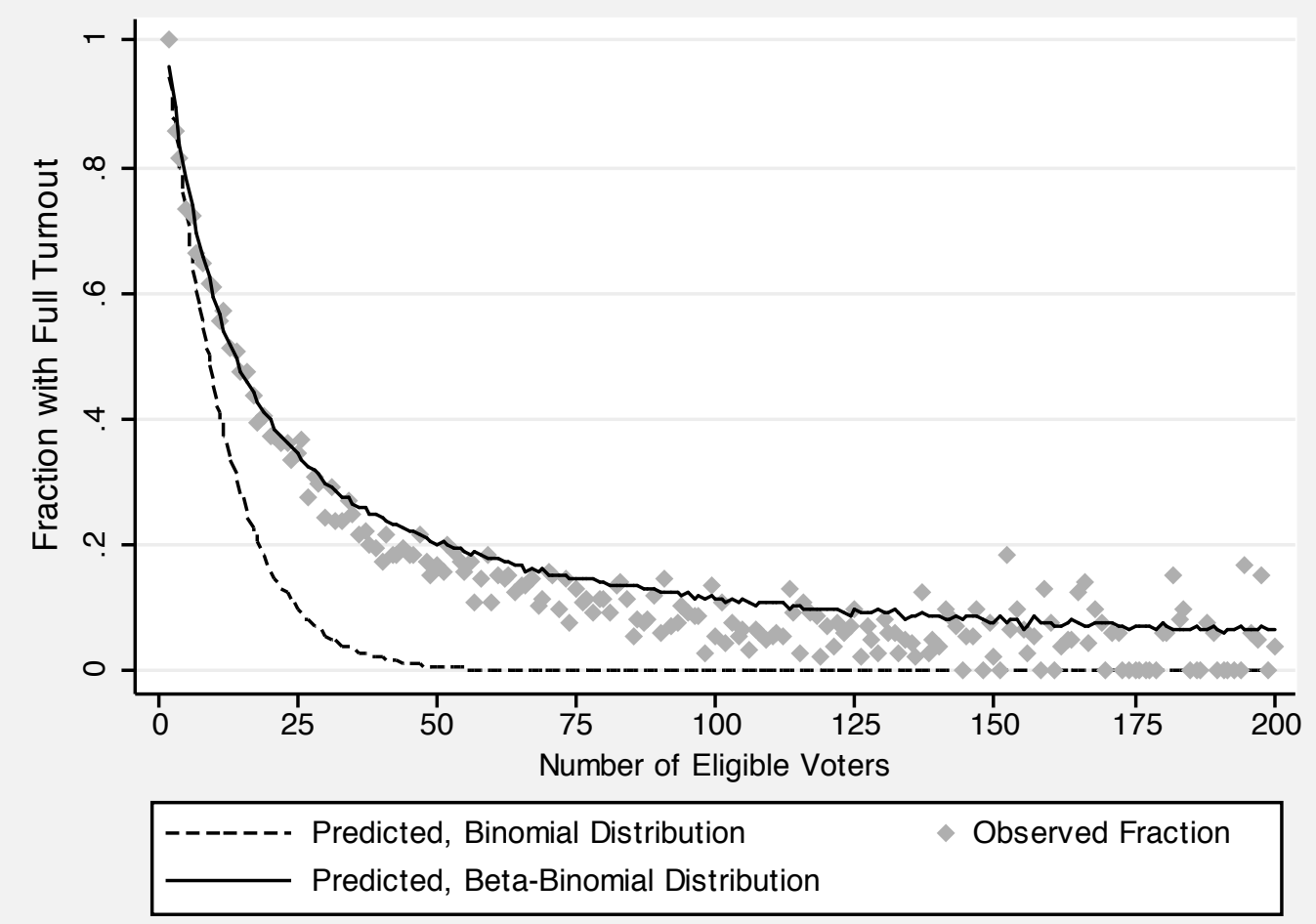

Figure 8: Probability Full Turnout, by Total Number of Eligible Voters. (Predicted fractions from binomial and beta-binomial mdoels in table 1.)

Can the variation across elections in the vote probability account for the high observed probability of full turnout relative to the binomial model? In order to investigate this question, I calculated the predicted full turnout probabilities from both the binomial and beta-binomial models described above. Figure 8 contains plots of the predicted full-turnout rates from the two models along with the observed full-turnout fractions by number of eligible voters. As shown in figure 6, the binomial model seriously under-predicts the likelihood of full turnout. The beta-binomial model, which allows for a distribution of vote probabilities across elections tracks the observed probability of full turnout much more closely. This is because, while both models estimate the mean turnout rate accurately, the mean turnout by number eligible is too low in elections with more than a few voters to generate enough elections with full turnout. The estimated beta distribution, as shown in figure 7, implies that there are substantial numbers of elections with very high turnout probablities (well above the estimated mean), and these are relatively likely to result in full turnout. 
Based on these results, I continue my investigation of the determinants of voter turnout using the beta-binomial model.

\section{$5 \quad$ Empirical Results}

The model developed in the previous section has a number of clear predictions regarding turnout and election outcomes. I analyze these in turn:

1. The relationship of turnout with election size.

2. The relationship between turnout and whether the election has an odd or even number of eligible voters.

3. The relationship of turnout with the expected closeness of an election.

4. The second-order relationship of election size with the marginal effect of closeness on turnout.

\subsection{Turnout and Election Size}

The probability that a worker's vote will be pivotal is inversely related to the size of the election. The fitted values for the mean turnout rate in on-site elections based on the betabinomial model presented in the second column of Table 1 are plotted in figure 9 along with a five-voter moving average of the observed turnout rate in elections with more than 30 eligible voters. ${ }^{25}$ These plots show a decline in both observed and predicted turnout from about 95 percent in the smallest elections to less than 89 percent in elections with 100 voters or more.

The convexity of the relationship of the turnout rate with election size is clear from this plot. The predicted decline in the turnout rate from an increase in election size from 10 to 20 eligible voters is 1.0 percentage point. The predicted decline in the turnout rate from an increase in election size from 100 to 110 eligible voters is 0.05 percentage points (or about one-twentieth the size).

\footnotetext{
25 I use the moving average because the relatively small number of large elections with particular numbers of eligible voters leads to substantial variation in average turnout. The predicted turnout rate is not a smooth function of the number eligible because of the year fixed effects in the model and changes in the size distribution of elections over time.
} 


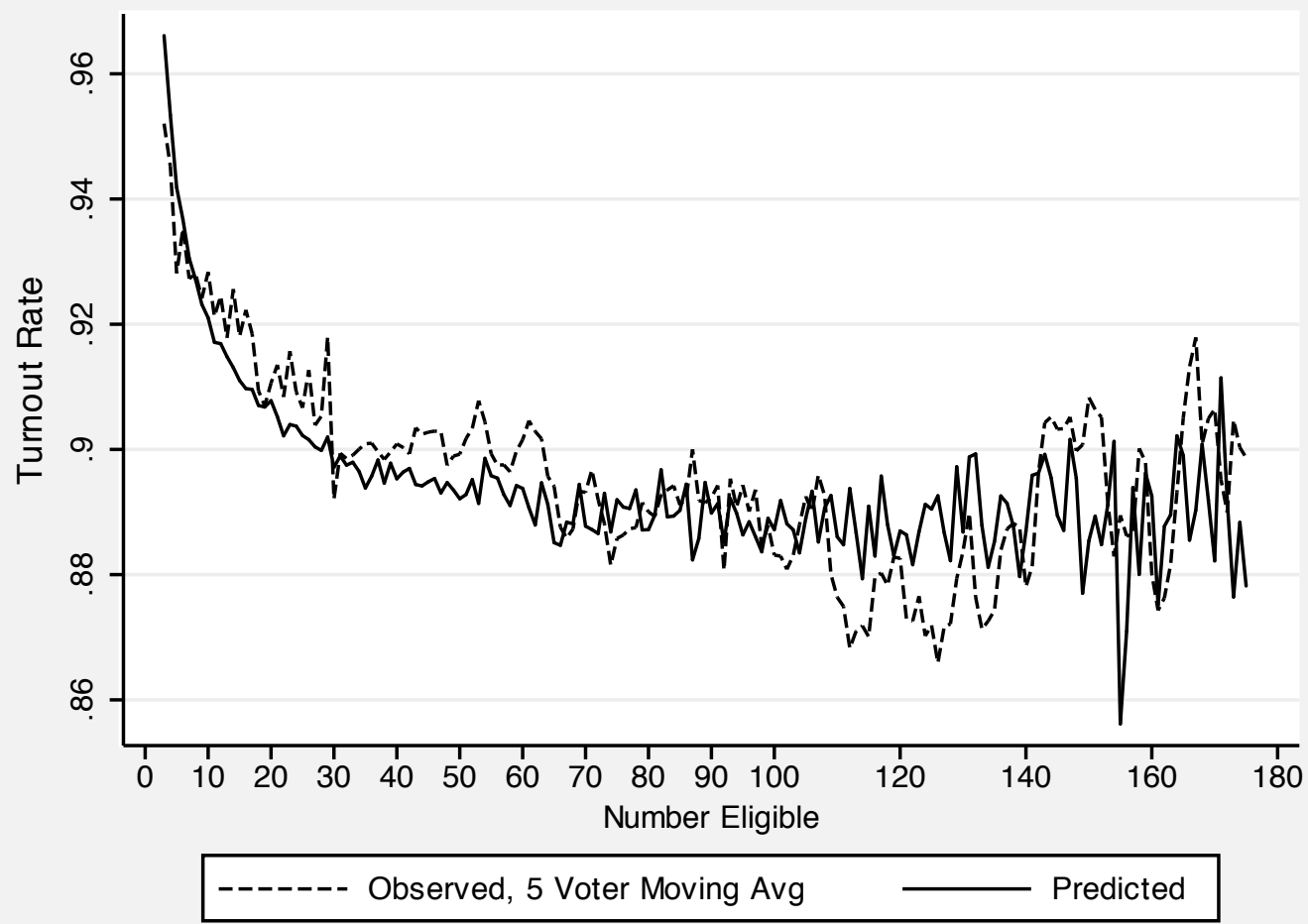

Figure 9: Turnout Rate by Number Eligible - 5-Voter Moving Average.

(Predicted based on $\hat{m}$, Table 1.)

The clear result is that turnout falls with election size as workers are less likely to be pivotal. However, it is also clear that turnout remains very high even in relatively large elections. This suggests that, while there is a margin of voters who may be considering the likelihood that their vote will be pivotal, most voters appear to vote regardless of the likely instrumentality of their vote.

\subsection{Turnout and the Odd/Even Distinction}

Given the fact that unions lose ties, the probability of being pivotal in small elections depends importantly on whether the number of eligible voters is odd or even and whether a particular voter is pro- or anti-union. A pro-union voter is pivotal when the election would be tied without his/her vote. In that case, they would cast the deciding vote in favor of union representation. Thus, pro-union voters are more likely to be pivotal in small elections with an odd number of eligible voters. Analogously, an anti-union voter is pivotal when the union 


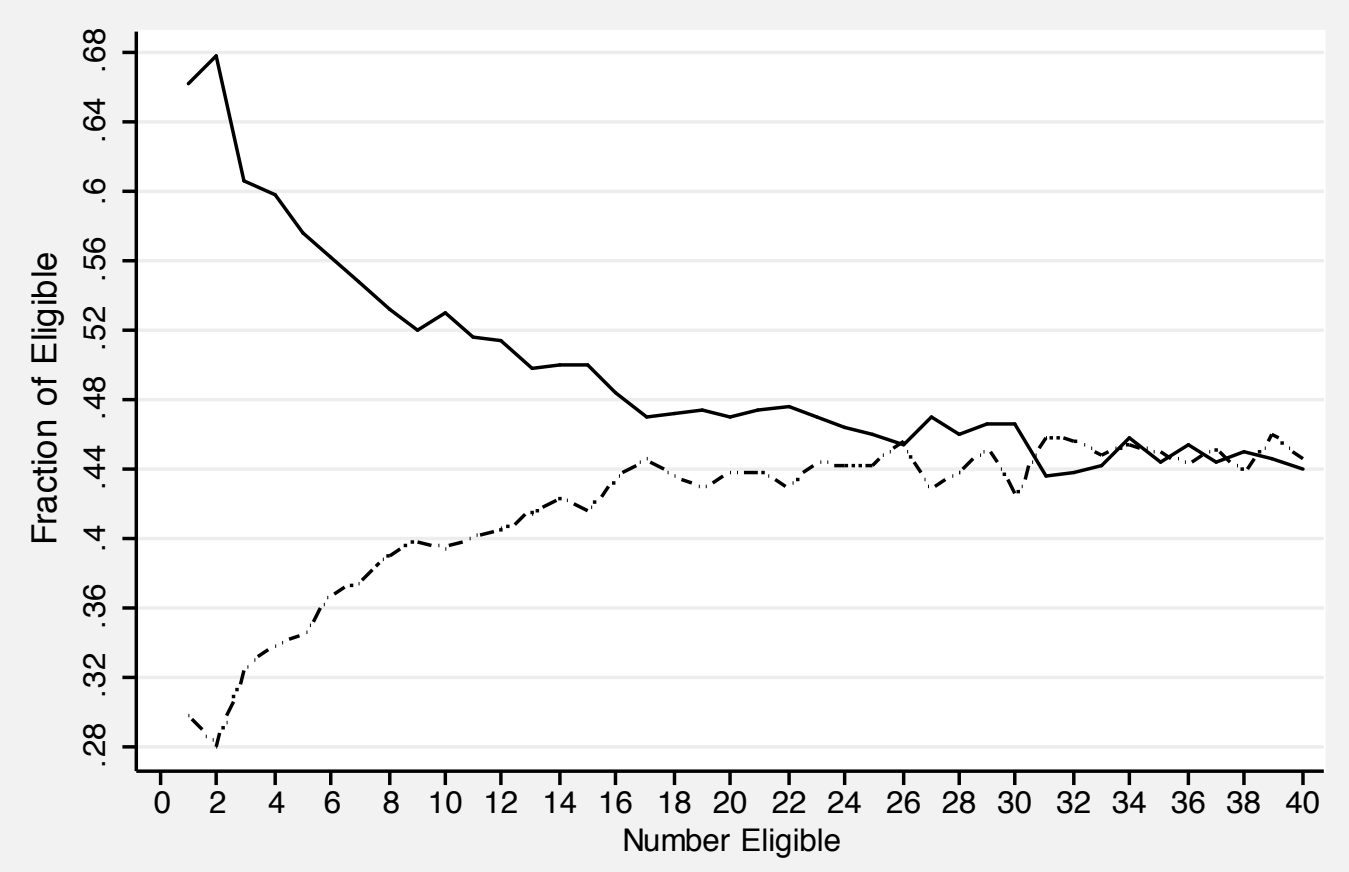

Fraction Voting Pro

-..- - - Fraction Voting Anti

Figure 10: Fraction Voting Pro- and Anti-Union, by Number Eligible.

would win by a single vote without his/her vote. Thus, anti-union voters are more likely to be pivotal in small elections with an even number of eligible voters.

While these differences offset for the most part in determining overall turnout, these considerations suggest that, other things equal, the fraction of eligible workers voting prounion will be higher in elections with an odd number eligible than in elections with an even number eligible. Similarly, the fraction of eligible workers voting anti-union will be higher in elections with an even number eligible than in elections with an odd number eligible.

Empirically, this prediction of the model finds no support in the data. Figure 10 contains plots of the fraction of those eligible voting for and against union representation by the number eligible. There is no evidence of either lower pro-union vote fractions or higher anti-union vote fractions in elections with an even number of eligible workers. ${ }^{26}$

${ }^{26}$ Simple $t$-tests of the difference in average vote fractions between even and odd elections show no signficant difference for either the pro-union or anti-union fractions. The $p$-value is greater than 0.9 in both cases. Estimation of models of the prounion vote share that control for election size also show no relationship between the pro- and anti-union vote shares and the "evenness" of the election. 


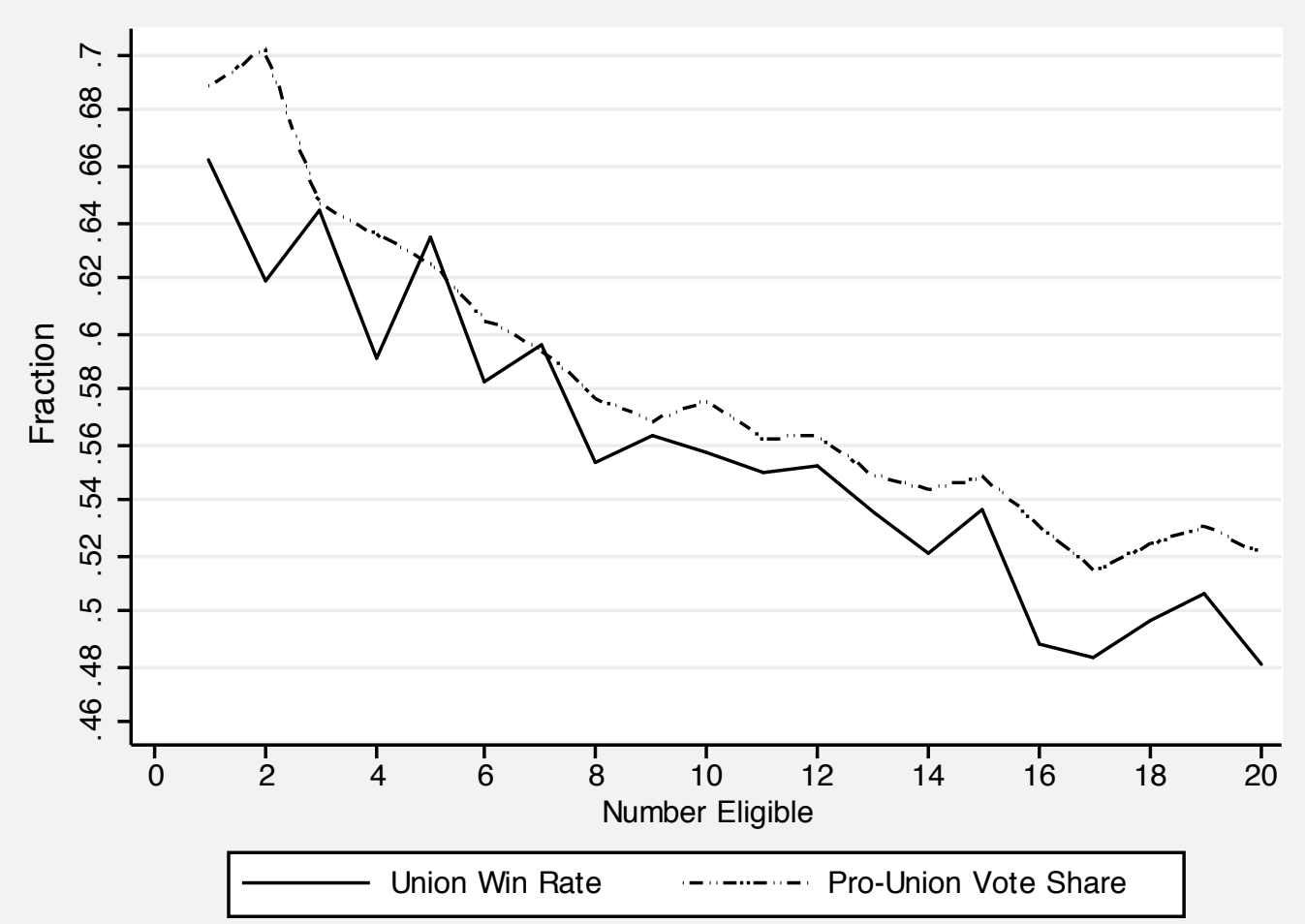

Figure 11: Union Vote Share and Win Rate, by Number of Eligible Voters

Figure 11 contains a plot of the union win rate and pro-union vote share in small elections by the number of eligible voters. There is clear evidence in elections with 10 or fewer voters that the union win rate is smaller in elections with an even number of eligible voters although there is not a systematic relationship of the "evenness" of the election with vote share. This suggests that unions do not completely offset the unions-lose-ties bias in the NLRA when selecting targets for organization. It may the case the union cannot predict precisely how many workers will be eligible to vote on the future election date given fluctuating employment levels and uncertainty about eligibility. It may also be the case that workers do not know the odd-even distinction or do not know whether their election has an even or and odd number of eligible voters in making their voting decisions.

Based on these results, I proceed assuming, where necessary, that the expected turnout rate in given elections does not differ between pro- and anti-union workers.

A final observation is that the prounion vote fraction is decreasing and the anti-union vote fraction is increasing in election size. This is consistent with the model of the union's 
organizing decision developed in section 3.1. In this model, the union will attempt an election where the probability of a union victory $(\theta)$ exceeds a critical value $\left(\theta^{*}\right)$. Let $p$ represent the probability that a worker will vote in favor of union representation. It is the case that, for any $p>0.5$, the probability of a union victory is increasing in election size. Thus, as election size increases, smaller $p$ 's satisfy the condition that $\theta>\theta^{*}$. The observed decline in pro-union vote share with election size is also consistent with the hypothesis that unions are more likely to contest larger elections where they have a smaller chance of winning $\left(\theta^{*}\right.$ is decreasing in election size).

\subsection{Turnout and Election Closeness}

Ignoring the odd-even distinction that differentially affects pro- and anti-union workers, the model predicts that a worker's vote is more likely to be pivotal when preferences are close to evenly split between pro- and anti-union. ${ }^{27}$ An even split of preferences is represented in the model developed in section 3.2 by $\mu=0.5$. While $\mu$ is not observed, I assume that elections differ in their underlying fraction pro-union and that there is a known prior distribution for $\mu$. I develop a useful proxy for $\mu$ based on the posterior distribution of $\mu$ given the observed pro-union vote share in that election. I calculate this distribution assuming that the expected turnout rate is the same among pro-union and anti-union workers.

As I noted earlier, a commonly-used distribution for probabilities is the beta distribution. On this basis, I assume that the prior distribution of $\mu$ is Beta such that

$$
g(\mu ; \rho, \nu)=\frac{\Gamma(\nu)}{\Gamma(\rho \nu) \Gamma((1-\rho) \nu)} \mu^{\rho \nu-1}(1-\mu)^{(1-\rho) \nu-1} .
$$

where the expected value of $\mu$ is $\rho$ and the variance of $\mu$ is $\sigma^{2}=\frac{\rho(1-\rho)}{(\nu+1)}$.

By the Bayes theorem, the distribution of $\mu$ conditional on observing $s$ pro-union votes among $n$ votes cast is

$$
f(\mu \mid s)=\frac{h(s \mid \mu) g(\mu)}{f(s)} .
$$

Assuming a binomial distribution for votes in a given election, the probability of observing

\footnotetext{
${ }^{27}$ I say "close to evenly split" rather than "evenly split" because pro-union voters are more likely to be pivotal when the expected vote is evenly split without their vote. In this case, the overall expected fraction pro-union is somewhat greater than 0.5 , with the difference from 0.5 declining with election size.
} 
$s$ pro-union votes among $\mathrm{n}$ votes cast is

$$
h(s \mid \mu)=\left(\begin{array}{l}
n \\
s
\end{array}\right) \mu^{s}(1-\mu)^{n-s} .
$$

Given that $\mu$ has a beta distribution, the unconditional distribution of the number of prounion votes is beta-binomial. This is

$$
f(s)=\left(\begin{array}{l}
n \\
s
\end{array}\right) \frac{\Gamma(\nu) \Gamma(\rho \nu+s) \Gamma((1-\rho) \nu+n-s)}{\Gamma(\rho \nu) \Gamma((1-\rho) \nu) \Gamma(n+\nu)} .
$$

Given these relationships and equation 24, the posterior distribution of $\mu$ given $s$ positive votes among $n$ voters is

$$
f(\mu \mid s)=\frac{\Gamma(n+\nu)}{\Gamma\left(s^{*}\right) \Gamma\left(n+\nu-s^{*}\right)} \mu^{s^{*}-1}(1-\mu)^{n-s^{*}+\nu-1},
$$

where $s^{*}=s+\rho \nu$. The posterior mean of $\mu$ given $s$ is

$$
E(\mu \mid s)=\frac{\Gamma(n+\nu)}{\Gamma\left(s^{*}\right) \Gamma\left(n+\nu-s^{*}\right)} \int_{0}^{1} \mu^{s^{*}}(1-\mu)^{n-s^{*}+\nu-1} d \mu .
$$

Noting that $\int_{0}^{1} \mu^{s^{*}}(1-\mu)^{n-s^{*}+\nu-1} d \mu$ is the Beta function with parameters $s^{*}+1$ and $n+\nu-s^{*}$, it is straightforward to show that

$$
E(\mu \mid s)=\left[\frac{n}{n+\nu}\right]\left(\frac{s}{n}\right)+\left[\frac{\nu}{n+\nu}\right] \rho .
$$

Thus, the posterior mean of the pro-union share in the workplace given the pro-union share of votes in the election is a weighted average of the observed vote share and the prior mean. ${ }^{28}$ The weight depends on the election size $(n)$ and the parameter $\nu$ that controls the variance of the Beta distribution for $\mu$. As the election size increases, the weight shifts from the prior mean $(\rho)$ to the observed pro-union vote share $(s / n)$. As the prior variance of $\mu$ decreases ( $\nu$ increases), the weight shifts to the prior mean.

The index I use to measure the (inverse) ex ante closeness of an election is the expectation of the squared difference between pro-union vote preference given the observed vote share and 0.5. After some algebra, this is

$$
E\left((\mu-0.5)^{2} \mid s\right)=0.25-\left[\frac{n+\nu}{n+\nu+1}\right] E(\mu \mid s)(1-E(\mu \mid s))
$$

${ }^{28}$ Derivation of this relationship relies on the definition of the Beta function as

$$
B(a, b)=\int_{0}^{1} \mu^{a-1}(1-\mu)^{b-1} d \mu=\frac{\Gamma(a) \Gamma(b)}{\Gamma(a+b)}
$$

and the property of Gamma functions that $\Gamma(Z+1)=Z \Gamma(Z)$. 


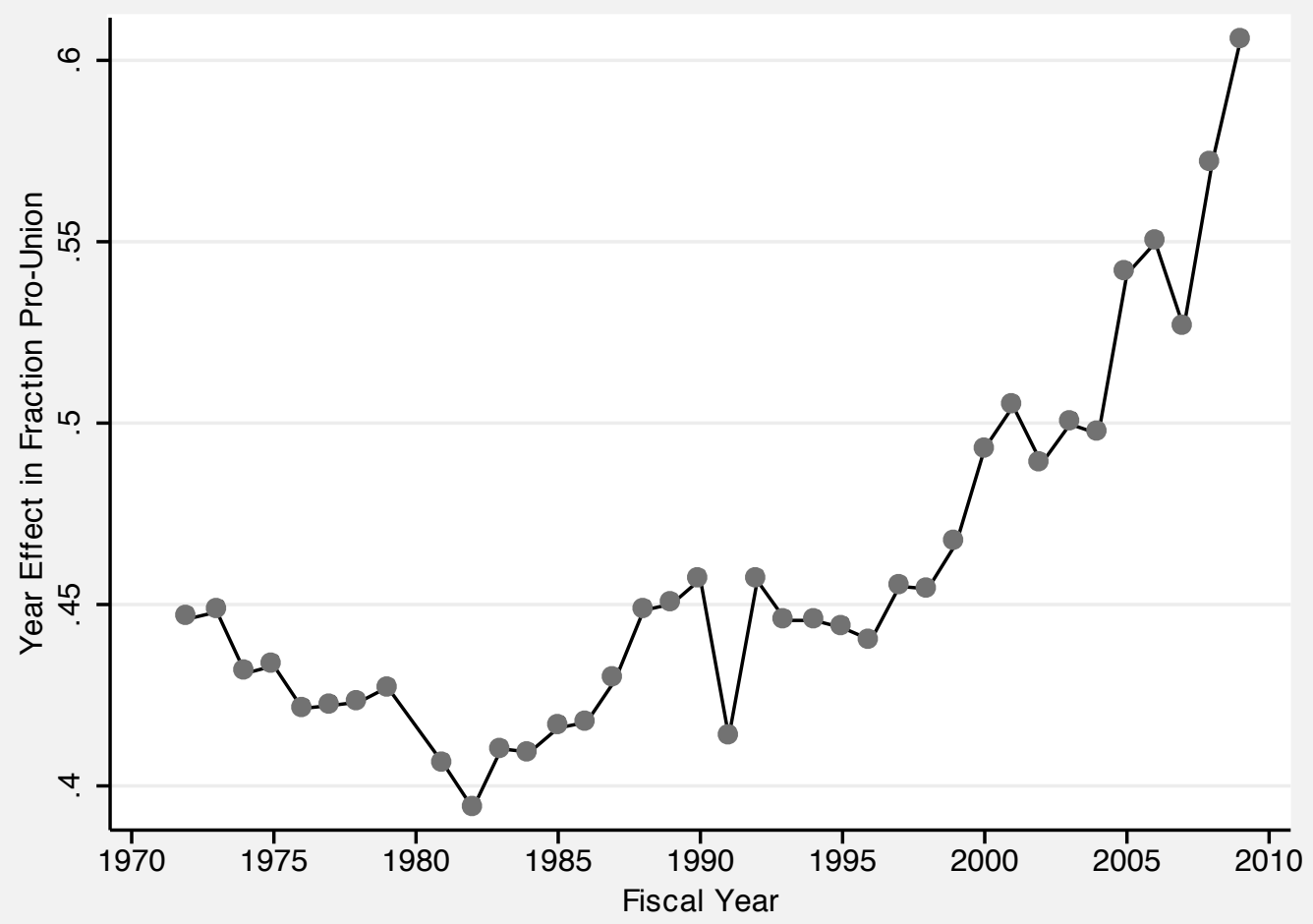

Figure 12: Year Effects on Estimated Mean Pro-Union Share

where $E(\mu \mid s)$ is defined in equation 29.

Calculation of the closeness index for each election requires data on the total number of votes cast and the number of prounion votes cast in each election along with estimates of the parameters $(\rho$ and $\nu$ ) of the Beta distribution of the fraction prounion $(\mu)$. The probability of $s$ pro-union votes of $n$ votes cast is defined in equation 25, and I use this probability statement to derive the likelihood function for the vote counts in the elections in my sample.

I specify the mean of the distribution of the prounion vote share to be a linear function of the inverse square root of the number eligible and a set of fiscal year fixed effects. The is

$$
\rho_{i t}=\beta_{0}+\beta_{1} \cdot\left(1 / \sqrt{N_{i t}}\right)+\theta_{t},
$$

for election $i$ in year $t$. I expect that the fraction pro-union will be negatively related to election size due to the union selection process outlined above. I estimated this beta-binomial model using data on the 75,300 on-site elections with between 2 and 200 eligible voters, at least 2 votes cast, and no challenged ballots. The estimated year effects $\left(\hat{\beta}_{0}+\hat{\theta}_{t}\right)$ are plotted in figure 12 , and these show a steady increase from 0.40 to about 0.55 since the mid-1980s. 


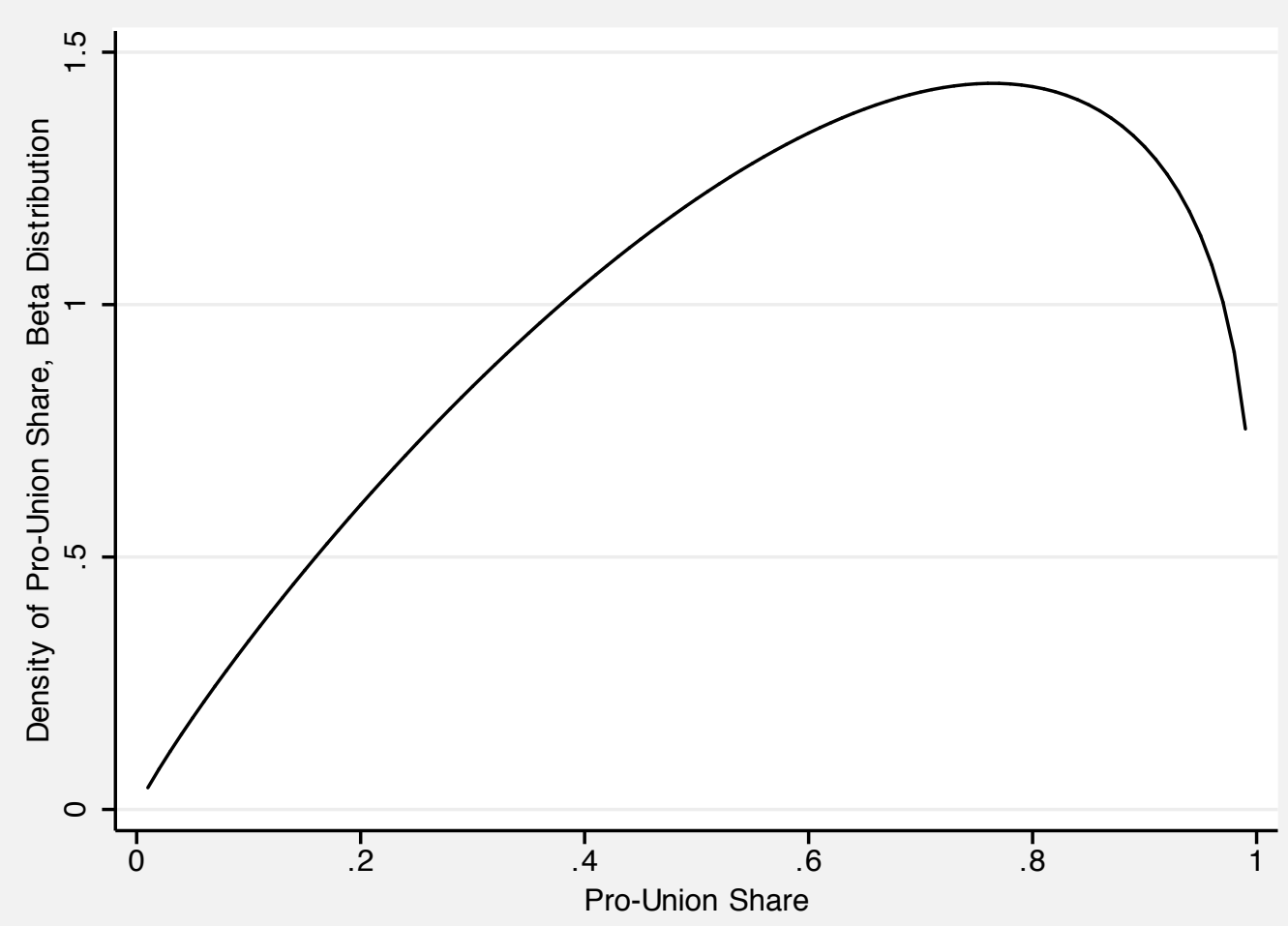

Figure 13: Beta Density Function of Pro-Union Share (Based on $\rho=0.59, \alpha=3.10$, corresponding to an election with 20 eligible voters and $\beta_{0}+\theta_{t}=0.5$.

This mirrors the trend in the pro-union vote share in the raw data illustrated in figure 2

The estimate of $\beta_{1}$ is 0.398 (s.e. $=0.008$ ), implying that the fraction pro-union is, as expected, inversely related to election size. If the year effect in a given year is 0.5 , then the model predicts an expected fraction pro-union of 0.7 in elections with 4 eligible voters. This falls substantially to 0.54 in elections with 100 eligible voters. The estimate of $\nu$ is 3.07 (s.e. $=0.024$ ), implying substantial heterogeneity across elections of a given size in the fraction pro-union. The implied standard deviation of $\mu$ is $\sqrt{\frac{\rho(1-\rho)}{\nu+1}}$. Evaluated at $\rho=0.59$ (the predicted value of $\rho$ in an election with 20 eligible voters and $\left.\beta_{0}+\theta_{t}=0.5\right)$, the standard deviation of $\mu$ is 0.244 . As an illustration, figure 13 contains a plot of the estimated density function for $\mu$ assuming $\rho=0.59$ and $\nu=3.07$, as estimated. Clearly, there is substantial variation across elections in pro-union sentiment.

With these estimates in hand, I predict the expected value of $\mu$ conditional on the observed pro-union vote share in each election in my sample based on equation 29. I then use this to calculated my inverse metric of the expected closeness of each election, the expected 


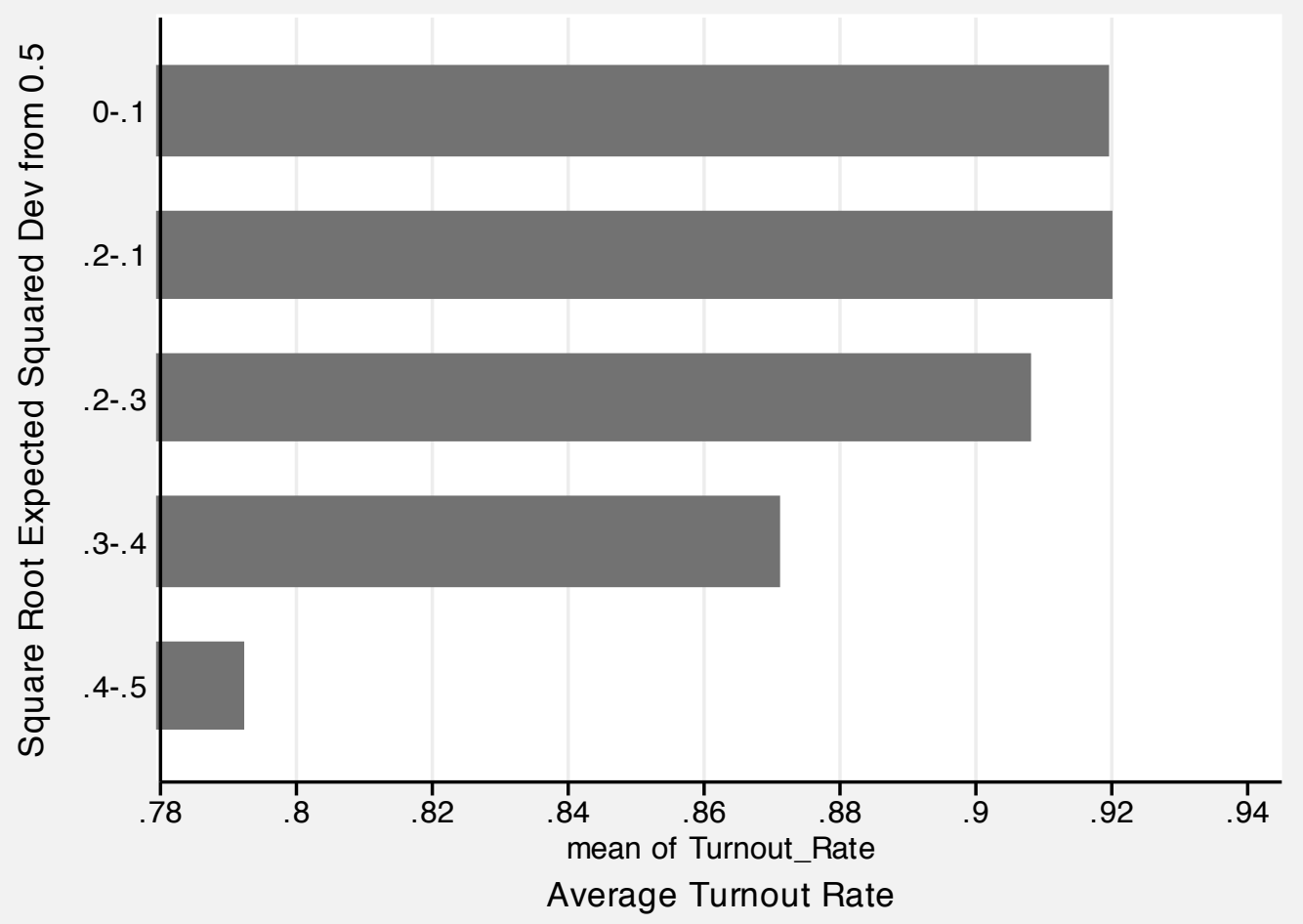

Figure 14: Turnout Rate, by Square Root of Expected Squared Deviation of Union Share from 0.5 (Equation 30).

value of the squared deviation of $\mu$ from 0.5 conditional on the observed pro-union vote share, as defined in equation 30 .

Figure 14 contains a bar graph of the average turnout rate (weighted by the number eligible) for various levels of the square root of the expected squared deviation of the prounion vote share from 0.5 . There is clear evidence that the turnout rate drops off substantially as this deviation exceeds 0.2 . This is consistent with a worker's vote/no-vote decision being positively related to the probability of being pivotal, reflecting a higher probability of being pivotal in close elections.

The first column of table 2 contains estimates of the beta-binomial model of election turnout that includes the measure of election closeness $\left(E\left((\mu-0.5)^{2} \mid s\right)\right)$ as well as the inverse square root of the number of eligible voters. The results show the strong inverse relationship between turnout and election size. They also show a strong positive relationship between turnout and expected election closeness. This is consistent with at least some workers making 
Table 2: Beta-Binomial Model Model of Voter Turnout

\begin{tabular}{|c|c|c|}
\hline Determinants of $m$ & (1) & (2) \\
\hline Constant & $\begin{array}{c}0.8802 \\
(0.0031)\end{array}$ & $\begin{array}{c}0.8986 \\
(0.0032)\end{array}$ \\
\hline $1 / \sqrt{N}$ & $\begin{array}{c}0.1687 \\
(0.0030)\end{array}$ & $\begin{array}{c}0.0829 \\
(0.0054)\end{array}$ \\
\hline$E\left((\mu-0.5)^{2} \mid s\right)$ & $\begin{array}{l}-0.3257 \\
(0.0087)\end{array}$ & $\begin{array}{l}-0.6476 \\
(0.0180)\end{array}$ \\
\hline$E\left((\mu-0.5)^{2} \mid s\right) / \sqrt{N}$ & & $\begin{array}{c}1.343 \\
(0.0646)\end{array}$ \\
\hline Year FE's & Yes & Yes \\
\hline$\alpha$ & $\begin{array}{c}7.100 \\
(0.0682)\end{array}$ & $\begin{array}{c}7.167 \\
(0.0690)\end{array}$ \\
\hline Log L & -125580.8 & -125383.2 \\
\hline
\end{tabular}

This model is estimated by maximum likelihood over the sample of 75,300 on-site elections (with a total of 2,014,616 eligible voters) with no challenged ballots, between 2 and 200 eligible voters and at least 2 votes cast. The base year is 2000 . Asymptotic standard errors are in parentheses.

decisions regarding turnout based on perceptions of the likelihood of being pivotal.

In order to illustrate how the distribution of the turnout rate is affected by closeness, figure 15 contains plots of the cumulative distribution functions of the beta distributions of of the vote probability for three different values of $\sqrt{E\left((\mu-0.5)^{2} \mid s\right)}$ based on the estimates in the first column of table 2 . The plots clearly show that where the election is expected to be close $\left(D E V=\sqrt{E\left((\mu-0.5)^{2} \mid s\right)}=0\right)$, the turnout distribution is lies to the right of the case where the election is expected to be not at all close $\left(D E V=\sqrt{E\left((\mu-0.5)^{2} \mid s\right)}=0.5\right)$.

\subsection{Turnout and the Interaction of Election Size and Election Closeness}

The usual statistical properties imply that there is more variation around the mean in small samples than in large samples. In the context of the likelihood of being pivotal, this implies that, for a given expected pro-union vote share, the likelihood that a voter will be pivotal falls with election size. On this basis, I expect that the marginal effect on turnout of the deviation of the expected pro-union vote share from 0.5 will fall in absolute value with election size.

In order to investigate this directly, I re-estimated the beta-binomial model of turnout 


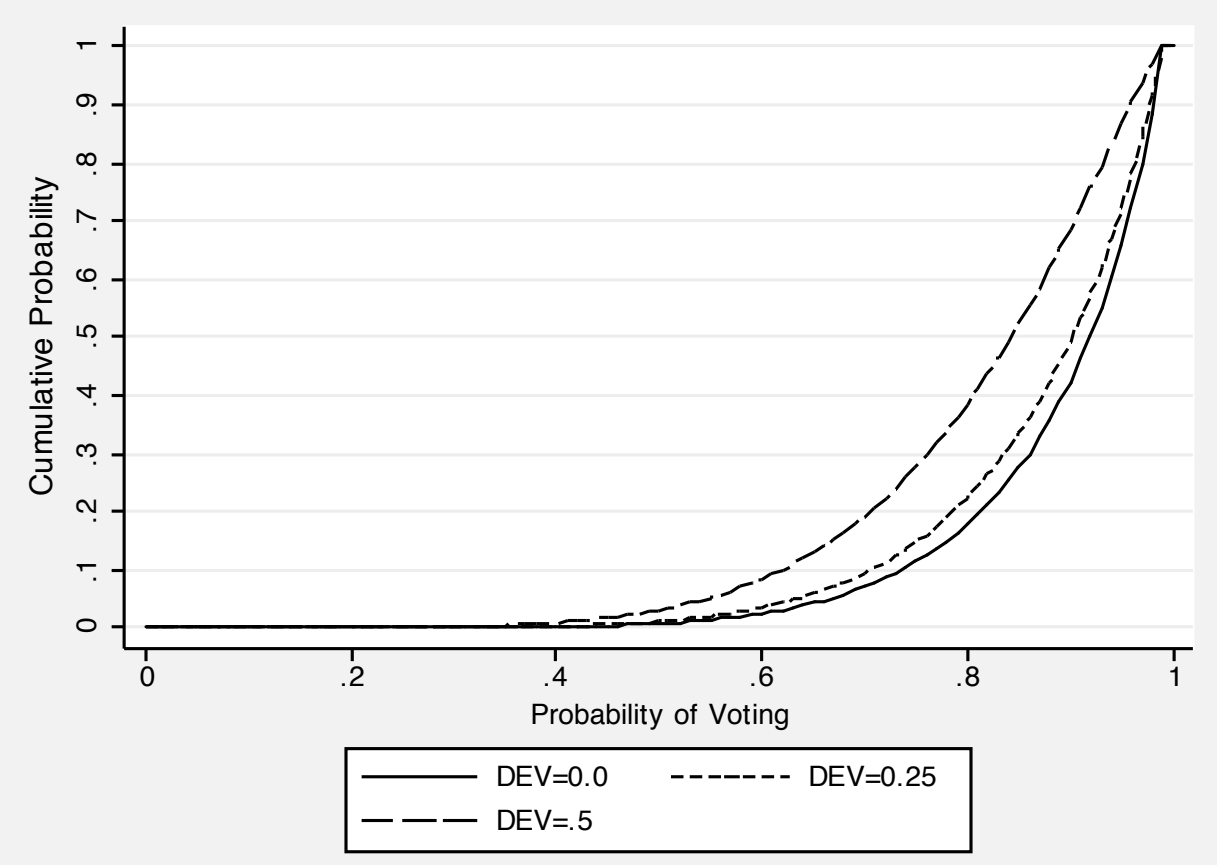

Figure 15: Cumulative Distribution Function of Vote Probability. The parameters of the Beta distribution are based on the estimates in column 1 of table 2 for $m=\left(0.9-0.3257 \cdot E\left((\mu-0.5)^{2} \mid s\right)\right.$ and $\alpha=7.100 . D E V=\sqrt{E\left((\mu-0.5)^{2} \mid s\right)}$

including an additional term in the expected turnout that is the interaction of the inverse number of eligible voters and $E\left((\mu-0.5)^{2} \mid s\right)$. These estimates are contained in the second column of table 2, and they yield the opposite result. It appears that the marginal effect of closeness increases in absolute value (becomes more negative) as the number of eligible voters increases. This is not consistent with voters deciding on the margin to vote based on their probability of being pivotal.

Once again, while I do not present the results here, I have also estimated both of the models in table 2 including additional controls for NLRB region, occupation, and industry. As before, adding these controls has no substantive effect on the coefficients of interest, and the estimate of $\alpha$ increases somewhat (to about 8.0), reflecting the fact that that there is less unobserved heterogeneity across election sites once variation in region, industry, and occupation are accounted for directly. 


\section{Implications of the Model}

The estimates of the beta-binomial model of turnout support the idea that consideration of the likelihood of being pivotal does affect the vote decision on the margin for at least some voters. The is based on the findings that 1) probability of voting is negatively related to the size of the election and 2) the probability of voting is positively related to the expected closeness of the vote. However, questions remain:

1. How important are the rational choice factors? Clearly (see figure 15), most elections have very high turnout, suggesting that most of those eligible vote regardless of the likelihood of being pivotal. I put some structure on this issue below using the estimates of the beta-binomial model.

2. Can the rational choice model account for the observed decline in turnout over time? To the extent the factors in the model related to the probability of being pivotal can account for the decline in voter turnout, the importance of rational choice analysis of the vote decision is reinforced. I examine this directly using the estimates of the model.

3. Is social pressure an important motivating factor in the vote decision? Social pressure is an alternative interpretation of the inverse relationship between turnout and election size. I examine this by estimating the relationship between turnout and election size in mail elections (where social pressure is likely much smaller).

\subsection{A Structural Interpretation: How Many Voters Consider the Likelihood of Being Pivotal?}

An interesting interpretation of the results presented here is based on the idea that there are two kinds of voters:

- Type I workers who vote regardless of the likelihood of being pivotal, and

- Type II workers who consider the likelihood of being pivotal in deciding whether or not to vote.

In the context of the model developed in section 3.2, Type I workers are those whose costs of voting, broadly defined, are zero or negative. Type II workers are those with positive voting 
costs. How many of each type exist in a given election is determined by the distribution of costs $(G(\cdot))$. Variation in this cost distribution is likely an important part of heterogeneity across elections in turnout.

One way to quantify the relative frequencies of the two types of voters is to consider the case where the probability of being pivotal is vanishingly small so that the observed distribution of turnout is the distribution of the share of Type I workers. The probability of being pivotal vanishes as the size of the election gets very large $(N \rightarrow \infty)$ and the election is not close (approximated by $\left.E\left((\mu-0.5)^{2} \mid s\right)=0.25\right)$. Substituting these values into the formula for the mean of the beta binomial using the estimates in the first column of table 2 and assuming the year 2000 fixed effect estimate $(=0.008)$, yields a predicted value for the mean of $0.791 .^{29}$ This suggests that, on average, about 80 percent of workers vote regardless of the likelihood of being pivotal and the remaining 20 percent, on average, consider whether or not their vote will be pivotal in deciding whether to vote. Given the average turnout rate in 2000 of about 0.9 , this implies that, on average, about half of those voters who consider the likely instrumentality of their vote do, in fact, vote.

By these calculations, there is considerable heterogeneity across elections in the share of voters who are Type I. Figure 16 contains a plot of the cumulative distribution function of the Type I share across elections calculated as the distribution of turnout in an election that is not close $\left(E\left((\mu-0.5)^{2} \mid s\right)=0.25\right)$ with an infinite number of voters. The median of this distribution is 0.81 , suggesting that half of all elections have at least 81 percent Type I workers. Additionally, almost 25 percent of elections have at least 90 percent Type I workers.

The conclusion is that most of those eligible vote without consideration of the likelihood that their vote will be pivotal. However, there is a substantial fraction, varying across elections, who do consider the effect of their vote on the outcome in deciding whether or not to turn out. 


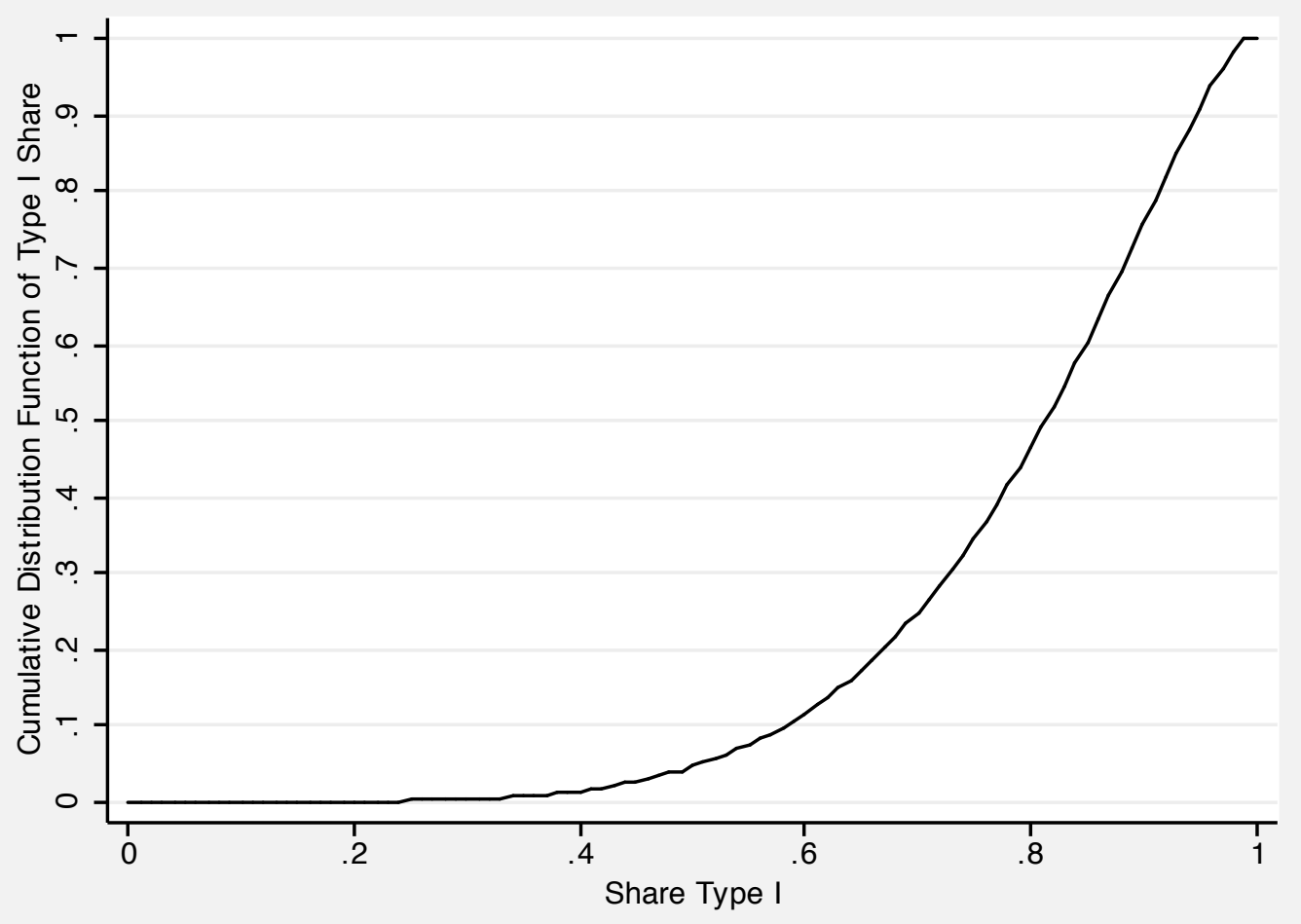

Figure 16: Cumulative Distribution Function of Share of Type I Voters. The parameters of the Beta distribution are based on the estimates in column 1 of table 2 for $m=0.791$ and $\alpha=7.1$, corresponding to an election in fiscal year 2000 that is not close with a very large number of eligible voters.

\subsection{Can the Rational Choice Model Account for the Decline in Turnout?}

As demonstrated in figure 4, average turnout in on-site elections fell from 92 percent to 84 percent between 1972 and 2008. I use the estimates of the year fixed effects from the beta-binomial model in column 1 of table 2 to examine the extent to which the turnout model can account for this decline. As a benchmark, I calculated the year fixed effects of a similar beta-binomial model that includes only the year fixed effects. This benchmark model includes neither the measure of the size of the election nor the measure of expected closeness. The results of this exercise are presented in figure 17. The plot of "year effects

29 Using the estimates in the second column of table 2 yields a smaller estimate for the share of Type I workers of 0.729 . I am less comfortable with this estimate given the fact that there are not many very large elections and the estimated main effect on $E\left((\mu-0.5)^{2} \mid s\right)$ is strongly affected by the presence of the interaction term estimated using a sample of predominantly smaller elections. 

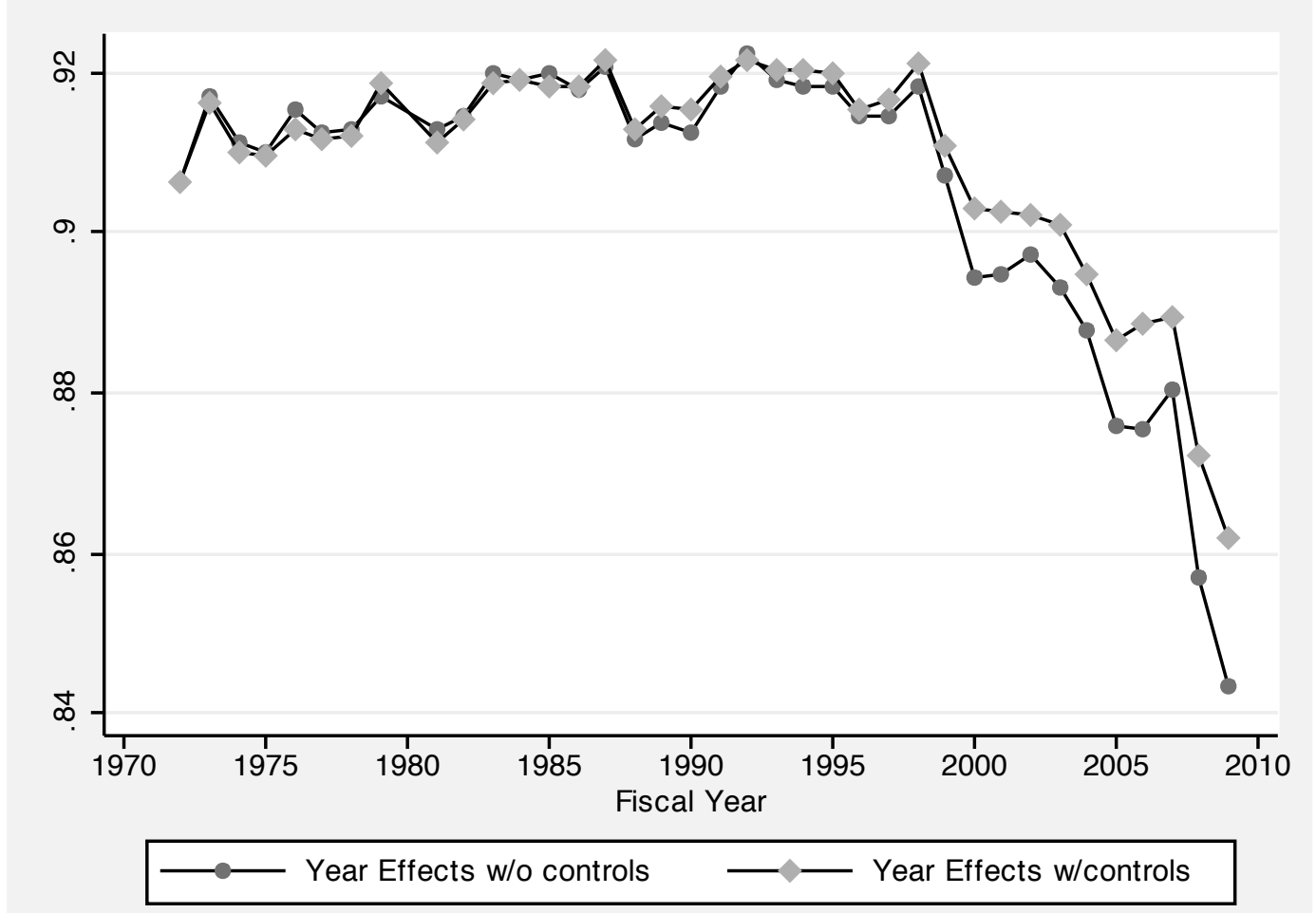

Figure 17: Adjusted and Unadjusted Mean Turnout Rates, on-site elections by year.

w/o controls" presents simply the year fixed effects from the benchmark model, and these approximate average turnout. The plot of "year effects w/controls" are the year effects from the model in the first column of table 2 shifted to match the benchmark value in the first year (1972).

There is clearly scope for the factors in the model related to the likelihood of being pivotal to account for at least some of the decline in turnout. Elections both increased in size and were expected to be less close over this period. The average number of eligible voters increased from 24 to 30 between 1972 and 2008. The average expected squared deviation of the pro-union vote share from 0.5 , the inverse measure of expected closeness, increased from 0.065 to 0.093 over the same period.

The results suggest that the rational choice model accounts for about 30 percent of the decline in average turnout. For example, the 2008 benchmark value of 0.857 represents a decline of 0.049 from the 1972 benchmark value. In contrast, the plotted 2008 year effect from the economic model is 0.872 , implying an unexplained decline of 0.034. Thus, 0.015 (31 percent) of the 0.049 decline in the turnout rate between 1972 and 2008 can be accounted 


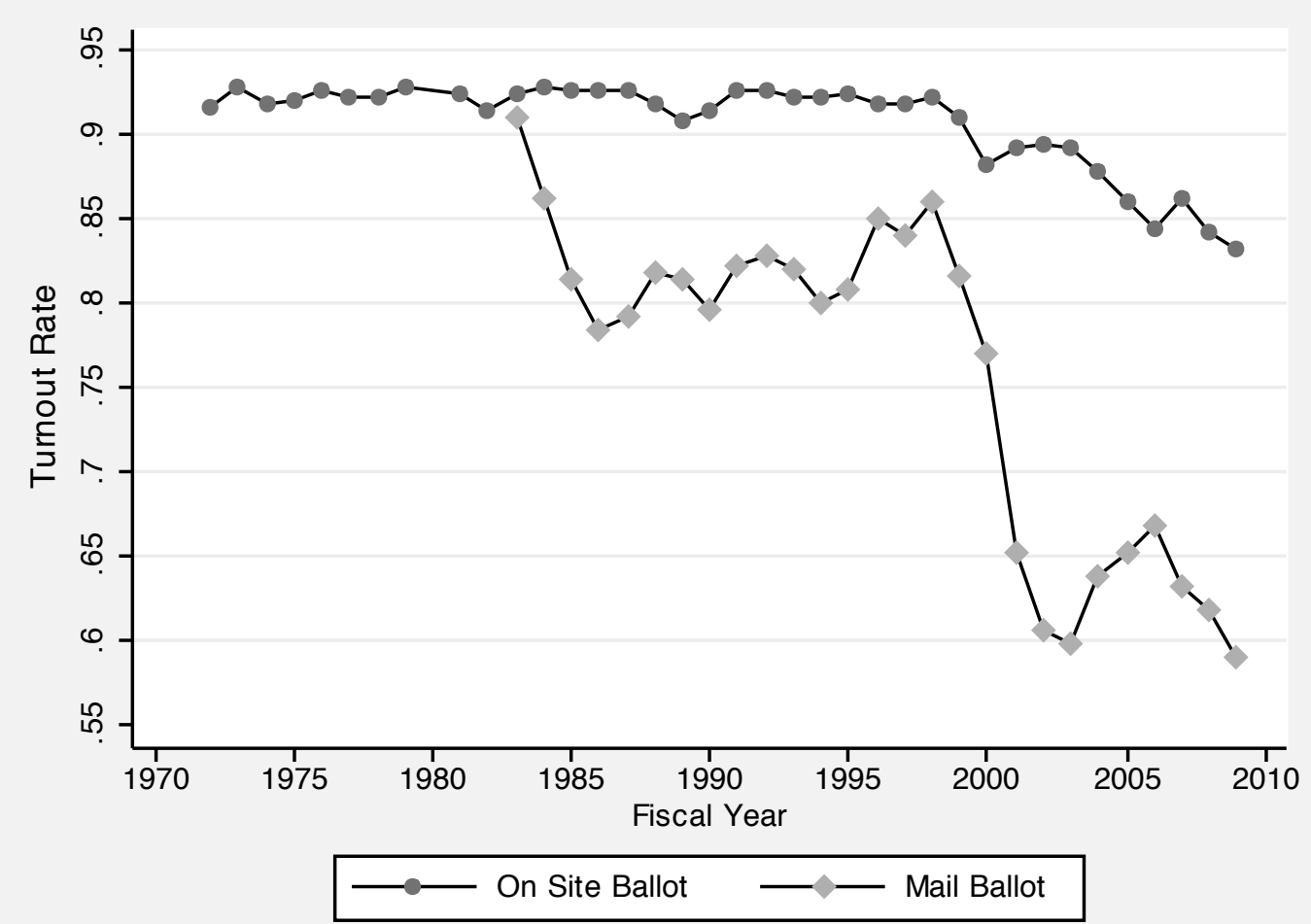

Figure 18: Turnout Rate, by Mode of Election - 3 yr. Moving Average for Mail Elections

for by the economic model.

\subsection{Social Pressure or Instrumentality: On-Site vs. Mail Elections}

As I discussed earlier, an important alternative to the model of voting based on consideration of the likelihood that a voter will be pivotal is the model based on social pressure. These two models have different predictions for the relationship between election size and turnout. While both models predict that the turnout will decline with election size in on-site elections, only the model based on instrumentality of the vote extends this prediction to mail elections (where social pressure will be largely absent).

The empirical analysis of mail elections is hampered by the fact that there are relatively few such elections. In the analysis sample used to estimate the beta-binomial model, there were 75,300 elections. There are only 1,845 mail elections that meet the same criteria.

The most obvious difference between mail and on-site elections is that turnout is much lower in mail elections. Figure 18 contains plots by year of turnout rates in on-site elections 


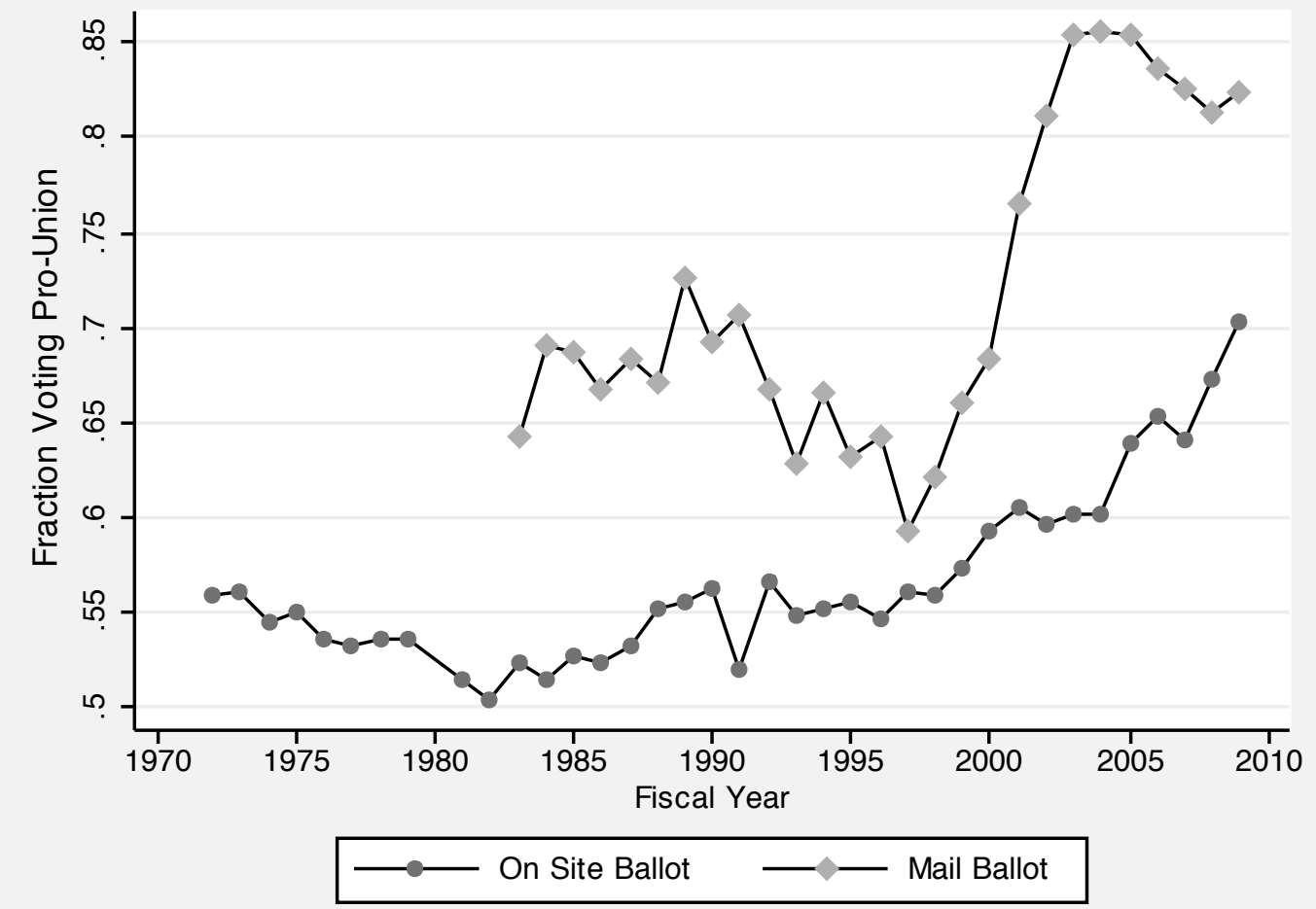

Figure 19: Pro-Union Vote Share, by Mode of Election - 3 yr. Moving Average for Mail Elections

and mail elections. ${ }^{30}$ While there is some drop-off in the average turnout rate in on-site elections, the turnout rate in on-site elections is substantially higher throughout than the turnout rate in mail elections. The turnout rate of elections with mail ballots declined sharply from about 85 percent in 1998 to about 60 percent in 2008. In contrast, over the same period, turnout rates in on-site elections fell from about 90 percent to about 84 percent.

Examining elections closed in fiscal 1984 or later, there is not a significant difference in the number eligible between on-site and mail elections. However, mail elections tended to be less close in outcome than on-site elections. Figure 19 contains plots of the average pro-union vote share over time by mode of election. The average pro-union vote share is greater in mail elections than in on-site elections, and it grows much more rapidly in mail elections after the late 1990s.

\footnotetext{
${ }^{30}$ Due to the small number of mail elections in any year, I plot the 3-year moving average of the turnout rate for mail elections.
} 
Table 3: Beta-Binomial Model Model of Voter Turnout

\begin{tabular}{l|cc} 
Variable & & \\
\hline & On-Site & Mail \\
Determinants of $m$ & $(1)$ & $(2)$ \\
\hline Constant & 0.8802 & 0.7333 \\
& $(0.0031)$ & $(0.0221)$ \\
$1 / \sqrt{N}$ & 0.1687 & 0.2475 \\
& $(0.0030)$ & $(0.0367)$ \\
$E\left((\mu-0.5)^{2} \mid s\right)$ & -0.3257 & -0.2338 \\
Year FE's & $(0.0087)$ & $(0.0670)$ \\
$\alpha$ & 7.100 & 3.660 \\
& $(0.0682)$ & $(0.1601)$ \\
\hline Log L & -125580.8 & -4484.9
\end{tabular}

This model is estimated by maximum likelihood over the samples of 75,300 on-site elections (with a total of 2,014,616 eligible voters) and 1845 mail elections (with a total of 52,820 eligible voters) with no challenged ballots, between 2 and 200 eligible voters and at least 2 votes cast. The base year is 2000. Asymptotic standard errors are in parentheses.

The data on pro-union vote shares in figure 19 suggests that there is scope for the economic model to account for the difference in turnout between mail and on-site elections. I already showed (figure 17) that changes in the factors affecting the likelihood of being pivotal, election size and expected closeness, can account for about 30 percent of the decline in turnout in on-site elections. Figure 19 suggests that, on average, mail elections are expected to be less close than on-site elections and that mail elections have become even less close over time. This could account for at least some of the sharp decline in turnout in mail elections shown in figure 18.

Table 3 contains estimates of the beta-binomial model of turnout separately for on-site and mail elections. Column 1 contains estimates for on-site elections (identical to column 1 of table 2) and column 2 contains estimates for mail elections. Comparison of the estimates for the two groups of elections provides a test of whether social pressure, potentially important in on-site elections but less important in mail elections, can account for the relationship between turnout and election size.

To the extent that social pressure is an important factor in the relationship between turnout and election size, we would expect to find a smaller coefficient on the size measure 
in determining mean turnout in mail elections than in on-site elections. The results are the opposite. The estimated coefficient on the size measure is significantly larger in mail elections $(p$-value of difference $=0.032)$. This suggests that social pressure to vote is not an important factor in the turnout decision.

It is important to note that this test does not rule out the importance of a norm that encourages voting. Indeed, it may be the case that such a norm accounts for the high general turnout rates in these elections. The finding that most voters vote without regard to the likelihood that their vote would be pivotal ("type I" voters) is consistent with the existence of this norm. The test simply is evidence against the idea that observability of the act of voting is an important factor.

The point estimate of the marginal effect of the inverse measure of closeness $(E((\mu-$ $0.5)^{2}(s)$ ) is significantly negative, as expected, in mail elections. This estimate for mail elections is smaller in magnitude than the corresponding estimate for on-site elections, though the difference is not statistically significant $(p$-value $=0.174)$.

I noted above that the growing gap between the pro-union vote share and 0.5 in mail elections could account for at least part of the sharp decline in turnout in mail elections. In order to investigate this directly in a manner parallel to the analysis for on-site elections in figure 17, I use the estimates of the year fixed effects from the beta-binomial model for mail elections in column 2 of table 3 to examine the extent to which the turnout model can account for this decline. As a benchmark, I calculated the year fixed effects of a similar model for mail elections that includes only the year fixed effects. The results of this exercise are presented in figure 20. The plot of "year effect w/o controls" approximates average turnout, and the plot of "year effect w/controls" based on the estimates in the first column of table 3 shifted to match the benchmark value in the first year (1984). The results suggest that, despite decreasing closeness of the mail elections over time and the implied reduction in turnout, the economic factors appear to explain little of the decline in turnout in mail elections.

A final exercise is to examine the extent to which the economic factors in the model can account for the difference between mail and on-site elections. To this end, figure 21 contains plots of the difference in estimated year effects between mail and on-site elections for two specifications. The first does not include controls for election size or expected closeness and approximates the observed difference in average turnout rates between mail and on-site 


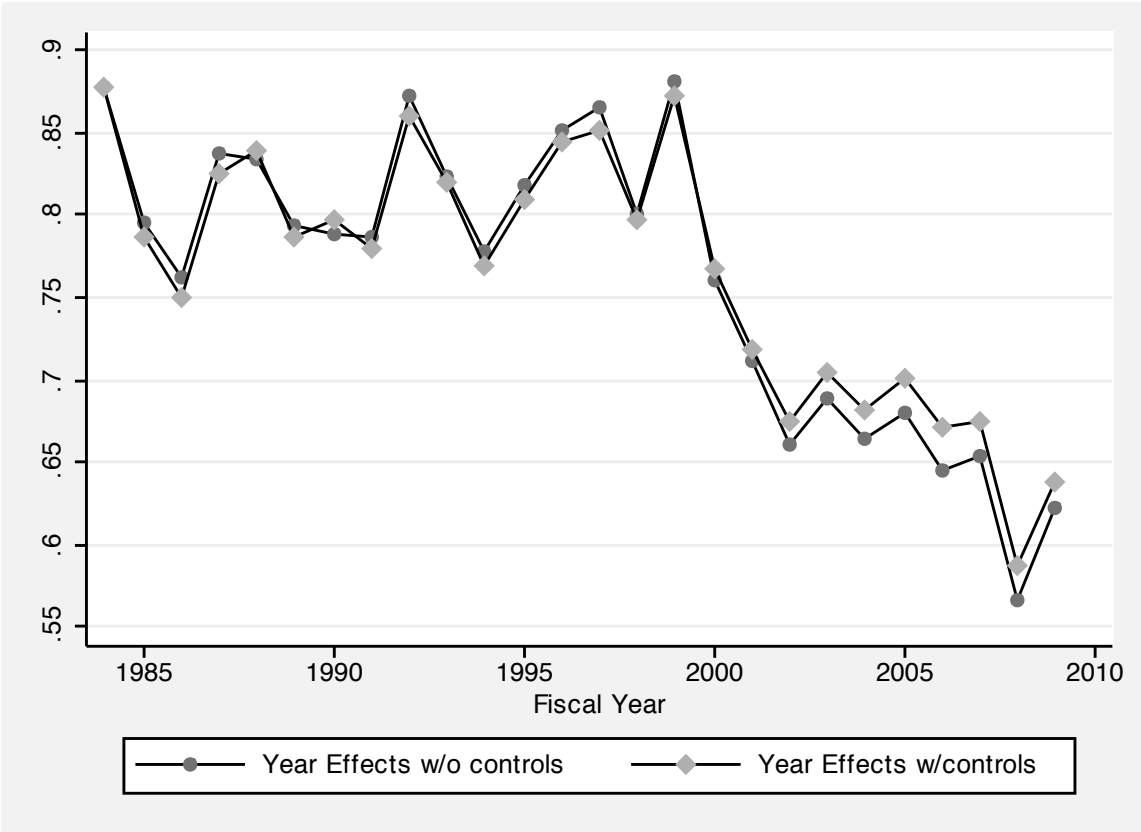

Figure 20: Adjusted and Unadjusted Mean Turnout Rates, mail elections by year.

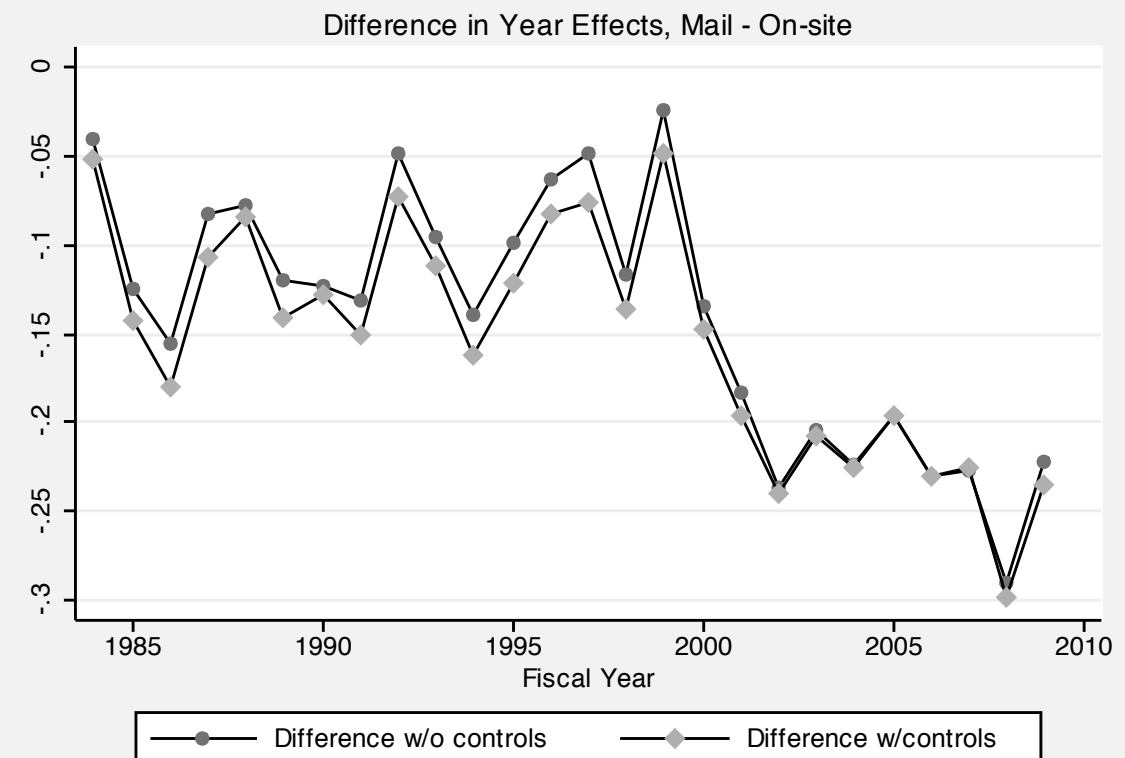

- Difference w/o controls: The difference in the estimated year effects in the model without controls for election size or closeness between mail and on-site elections.

- Difference w/controls: The difference in the estimated year effects in the model with controls for election size or closeness between mail and on-site elections.

Figure 21: Difference in Year Effects between Mail and On-Site Elections, by presence of economic controls and year. 
elections. The second includes these controls. The results clearly indicate that the variables measuring size and closeness, do not account for any of the difference in turnout between mail and on-site elections.

In the end, the mail elections, which constitute only a small fraction of all elections, appear to have substantially lower turnout than on-site elections for reasons that are not related to the likelihood that a voter will be pivotal. It may be that mail elections are costlier (in terms of time, effort, memory, etc.) than are on-site elections held in the workplace. However, this would not explain the sharp decline over time in turnout in mail elections. However, it does appear to be the case that, within mail elections, turnout is strongly negatively related to both election size and expected closeness.

I conclude that social pressure is not an important factor in explaining the inverse relationship found in on-site elections between election size and turnout.

\section{Final Comments}

It is clear from the analysis that most workers vote without consideration of the likelihood that they will be pivotal. But it is also clear that at least some workers, albeit a minority in most cases, understand in general terms how likely it is that they will be pivotal in deciding whether or not to vote. This is reflected both in lower turnout rates in larger elections and in higher turnout rates in elections where preferences are relatively evenly split. However, the results suggest that workers do not take into account the precise calculus defined in section 3.2 when deciding whether or not to vote. They do not appear to consider the secondorder interaction between election size and closeness. Neither do they appear to consider the specific rules that lead to the asymmetry between even and odd elections. This might reflect a lack of understanding of the election rules regarding ties or a lack of information about whether the number eligible is odd or even.

It is worth considering whether there are alternative interpretations for the support that is found for the rational choice model of voting. One possibility that I explored is that social pressure in the workplace, where the workplace is also the election site, might be important in getting people to vote. The reasonable assumption that social pressure is likely stronger in smaller elections than larger elections, one would expect to find a weaker relationship between turnout and election size in mail elections. However, I find the opposite. This 
implies that direct social pressure, enforced through observability of the act of voting, is not an important factor.

An alternative view of social pressure is that it is simply is the mechanism through with workers are made aware that an election will be close or that their vote is more likely to matter. In this case, social pressure is part of a rational choice decision process. More generally, there may be variation in social pressure or a general norm to vote that is an important driver of the heterogeneity in turnout rates (or Type I share) across elections.

The factors in my model related to the likelihood that a vote will be pivotal can account for about 30 percent of the decline in voter turnout in on-site NLRB representation elections in recent years. It is not clear what accounts for the remainder of the decline.

There are limits to how far the lessons learned by studying turnout in NLRB representation elections can be generalized to larger political elections. This is for several reasons. First, even relatively small local elections are much larger than most elections studied here. Second, the physical cost of voting in political elections is higher since the elections are generally held at a location to which the voter must travel while the NLRB representation elections are held in the work place. Finally, the stakes in a political election for an individual are generally lower than in an election which can fundamentally alter the employment situation. All of these factors likely contribute to the higher turnout observed in NLRB representation elections. 


\section{References}

Beck, Nathanial. "The Paradox of Minimax Regret," American Political Science Review 69 September 1975: 918.

Coate, Stephen, Michael Conlin, and Andrea Moro. "The Performance of the Pivotal-Voter Model in Small Scale Elections: Evidence from Texas Liquor Referenda." Journal of Public Economics 92, 2008: 582-596.

Cooke, William N. "The Failure to Negotiate First Contracts: Determinants and Policy Implications." Industrial and Labor Relations Review 38(2) 1985: 163-178.

Downs, Anthony. An Economic Theory of Democracy, New York, Harper \& Brothers, 1957.

Farber, Henry S. "Union Success in Representation Elections: Why Does Unit Size Matter?" Industrial and Labor Relations Review, January 2001. pp. 329.348.

Farber, Henry S. and Bruce Western. "Accounting for the Decline of Unions in the Private Sector, 1973-1998," Journal of Labor Research, Summer 2001. pp. 459-485.

Farber, Henry S. and Bruce Western. "Ronald Reagan and the Politics of Declining Union Organization," British Journal of Industrial Relations, September 2002. pp. 385-401.

Freeman, Richard B. "Why are Unions Faring so Poorly in NLRB Representation Elections?" in T. A. Kochan, ed. Challenges and Choices Facing American Labor, Cambridge MA, MIT Press, 1985.

Frerejohn, John A. and Morris P. Fiorina. "The Paradox of Not Voting: A Decision Theoretic Analysis," American Political Science Review 68 June 1974: 525-36.

Frerejohn, John A. and Morris P. Fiorina. "Closeness Only Counts in Horseshoes and Dancing,' ' American Political Science Review 69 September 1975: 920-925.

Funk, Patricia. "Social Incentives and Voter Turnout: Evidence from the Swiss Mail Ballot System," Mimeo, Universitat Pompeu Fabra, November 2008.

Gould, William B. IV. Agenda for Reform: The Future of Employment Relationships and the Law, Cambridge, Massachusetts. MIT Press, 1993.

Johnson, Susan. "Card Check or Mandatory Representation Vote? How the Type of Union Recognition Procedure Affects Union Certification Success," Economic Journal 112 April 2002: 344-361. 
Knack, Stephen. "Civic Norms, Social Sanctions, and Voter Turnout," Rationality and Society 4 1992, 133-156.

Ledyard, J. "The Paradox of Voting and Candidate Competition: A General Equilibrium Analysis," in Essays in Contemporary Fields of Economics, G. Horwich and J. Quirk, eds., Purdue University Press, 1981.

Levine, David K. and Thomas R. Palfrey. American Political Science Review 101 February 2007: 143-158.

Levy, Paul Alan. "The Unidimensional Perspective of the Reagan Labor Board." Rutgers Law Journal 16 1985: 269-390.

Mayer, Lawrence S. and I.J. Good. "Is Minimax Regret Applicable to Voting Decisions?," American Political Science Review 69 September 1975: 916-917.

Palfrey, Thomas R. and Howard Rosenthal. "A Strategic Calculus of Voting," Public Choice 41 1983: pp. 7-53.

Palfrey, Thomas R. and Howard Rosenthal. "Voter Participation and Strategic Uncertainty," American Political Science Review 79 September 1985: 62-78.

Prosten, Richard. "The Longest Season: Union Organizing in the Last Decade, a/k/a How Come One Team Has to Play with its Shoelaces Tied Together?" Proceedings of the Thirty-First Annual Meeting of the Industrial Relations Research Association 1978: 240-249.

Riker, William H. and Peter C. Ordeshook. American Political Science Review 61 March 1968: 25-42.

Stephens, Stephen V. "The Paradox of Not Voting: Comment," American Political Science Review 69 September 1975: 914-915.

Strom, Gerald S. "On the Apparent Paradox of Participation: A New Proposal," American Political Science Review 69 September 1975: 908-913.

American Political Science Review 69 September 1975: 916-917.

Weiler, Paul C. "Promises to Keep: Securing Workers' Rights to Self-Organization under the NLRA," Harvard Law Review 96(8), June 1983 :351-420.

Weiler, Paul C. "Striking a New Balance: Freedom of Contract and the Prospects for Union Representation." Harvard Law Review 981984 :351-420.

Weiler, Paul C. Governing the Workplace. Cambridge MA: Harvard University Press, 1990. 